المجلة الدولية للدراسات التربوية والنفسية

بحث رقم 20

المجلد التاسع، العدد الثاني، 709:690

نيسان (2021)

\title{
القيادة التشاركية وعلاقتها بالثقافة التنظيمية لدى مديري المدارس الحكومية الأساسية في محافظة قلقيلية من وجهة نظر المعلمين

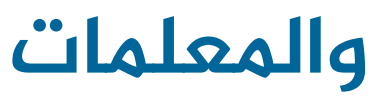

شادي خالد قشوع

باحث تربوي، برنامج دكتوراه الإدارة التربوية الجامعة العربية الأمريكية- فلسطين
جولتان حسن حجازي

أستاذ علم النفس

جامعة فلسطين التقنية، خضوري- فلسطين joltanhijazi@gmail.com 


\title{
القيادة التشاركية وعلاقتها بالثقافة التنظيمية لدى مديري المدارس الحكومية الأسساسية في محافظة قلقيلية من وجهة نظر المعلمين والمعلمات
}

\author{
جولتان حسن حجازي \\ أستاذ علم النفس- جامعة فلسطين التقنية/ خضوري- فلسطين \\ joltanhijazi@gmail.com

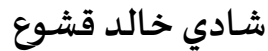 \\ باحث تربوي، برنامج دكتوراه الإدارة التربوية- الجامعة العربية الأمريكية- فلسطين
}

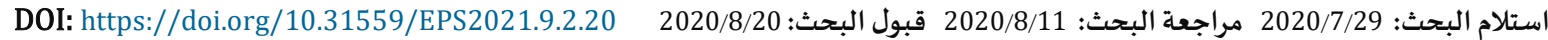

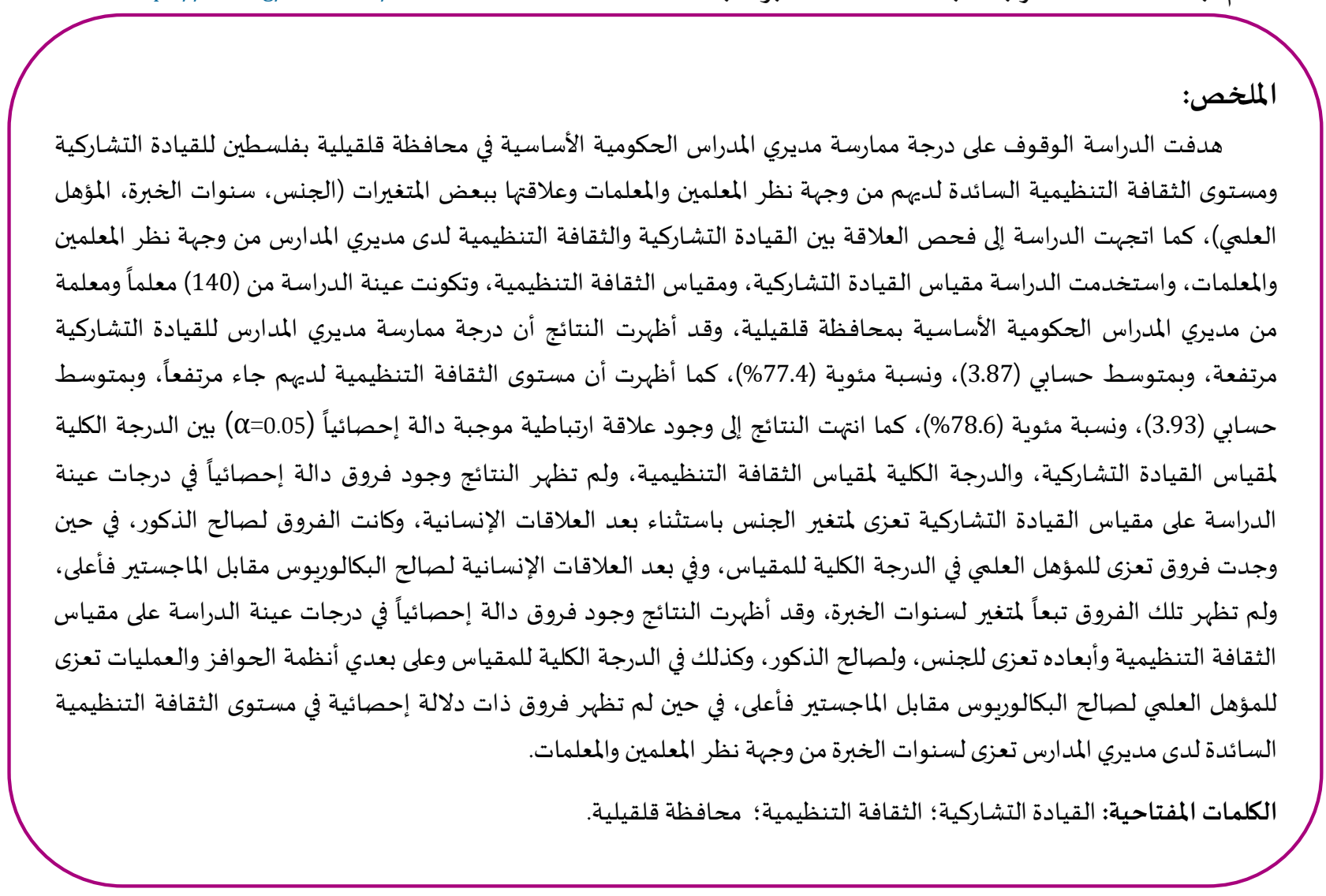

المقدمة:

تشكل القيادة محوراً هاماً لكل مؤسسة من المؤسسات على كافة الأصعدة؛ لأها تمثل الأنشطة التي يمارسها المسؤول الإداري تجاه العاملين في

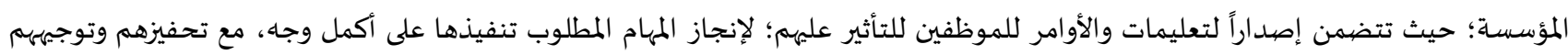

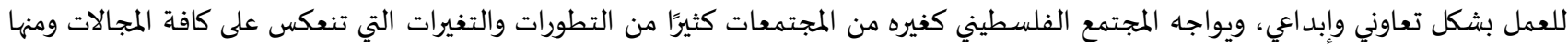

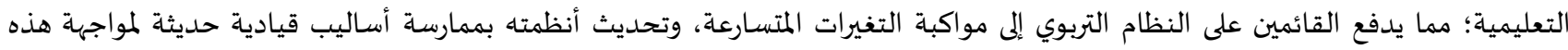


ويُعد النظام التربوي الذي يرتكز على القيادة الناجحة هو الأفضل؛ حيث تعمل هذه القيادة بخطوات جريئة وبنّاءة على تحقيق أهداف التربية

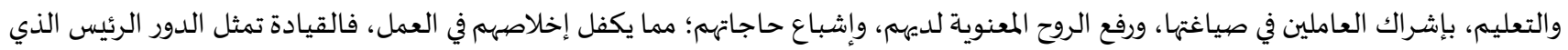

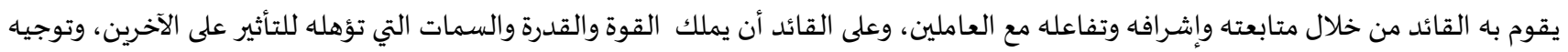

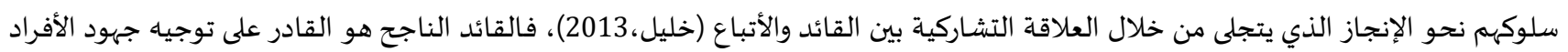
نحو تحقيق الأهداف من خلال قدرته على التأثير على سلوكهه، وجعل العمل الإداري أكثر فعالية وديناميكية، وهو القادر على التأثلى التير على العاملين،

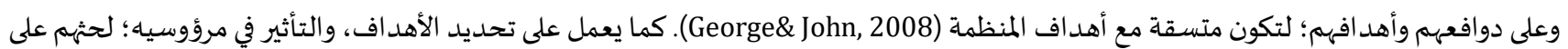
العمل، وخلق التعاون بين الموظفين (شقير، 2011)، وتضافر جهودهم لتحقيق أهد اف المؤسسة التعليمة (الكردي، 2014).

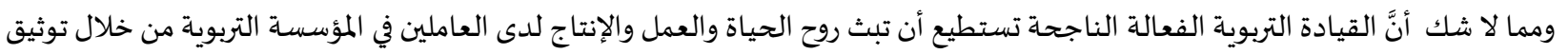

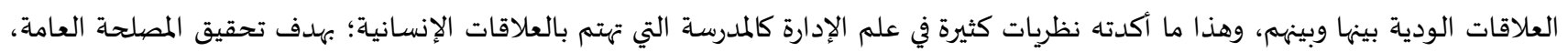

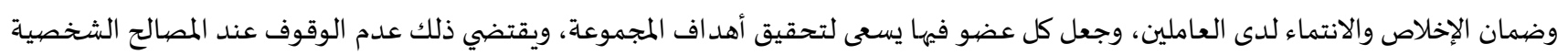

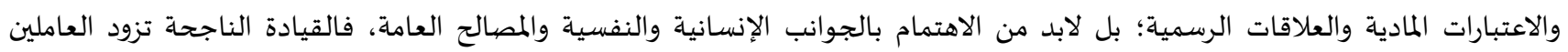

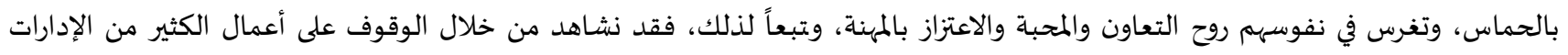

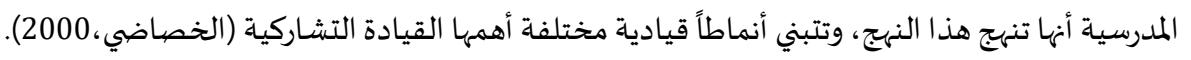

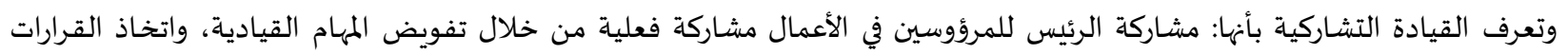

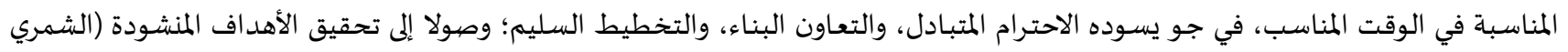

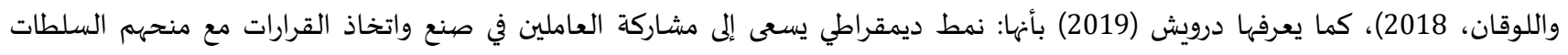

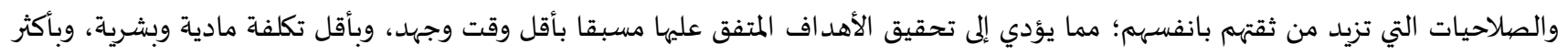

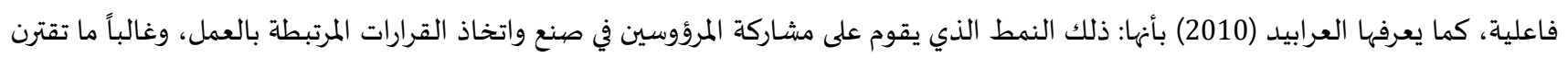

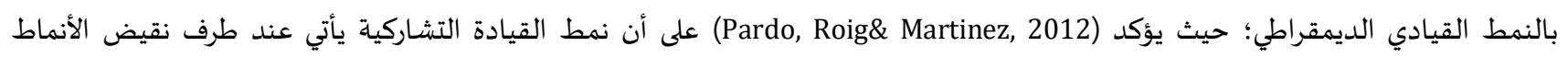

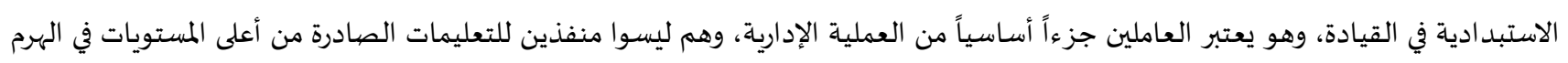

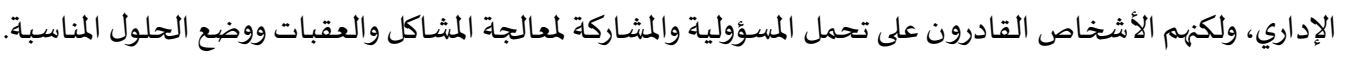

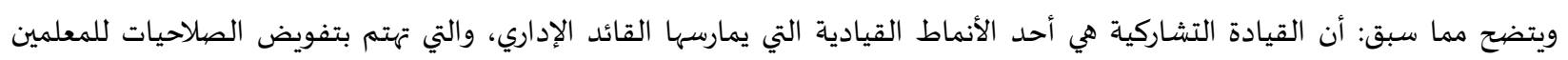

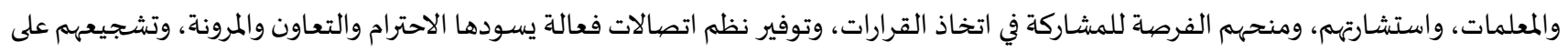

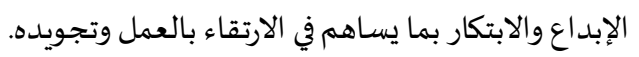

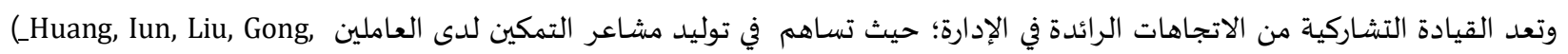
(2010، وتهتم بالتأثير والإقناع الشخصي للآخرين، وتعطي أهمية كبيرة للمرؤوسين بعيداً عن التهديد والتخويف، وهدفهاتها الأساسي احترام شخصية الآدية

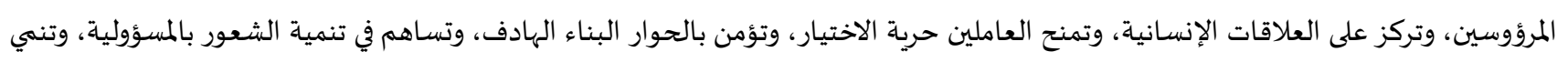

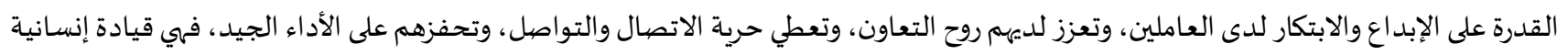

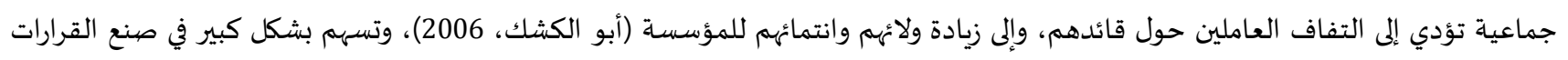

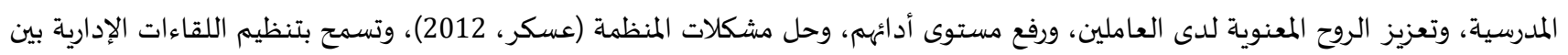

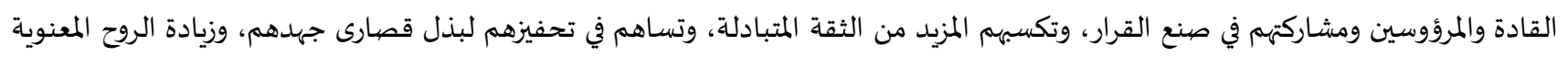

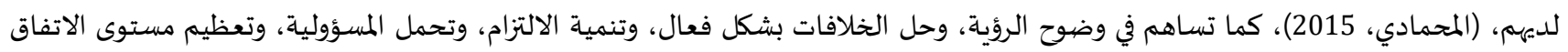

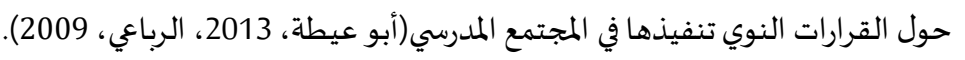

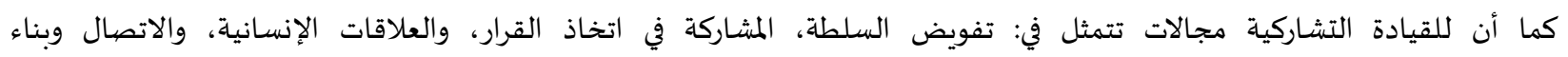

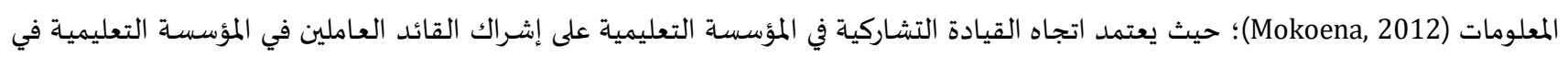

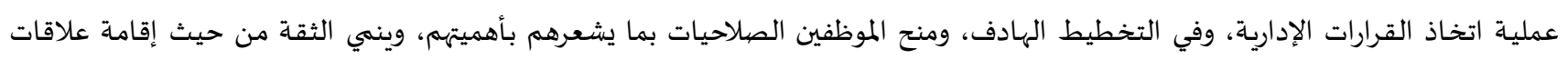

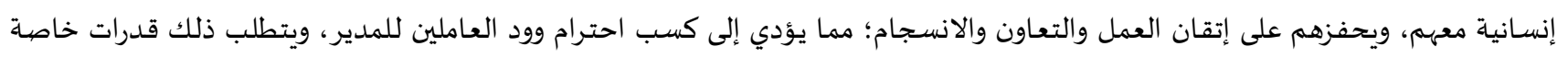

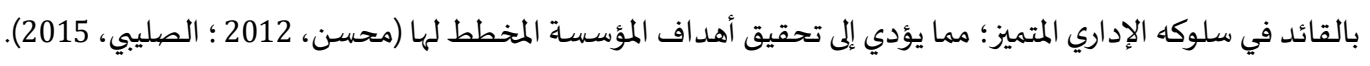

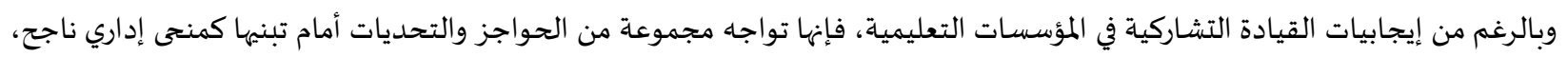

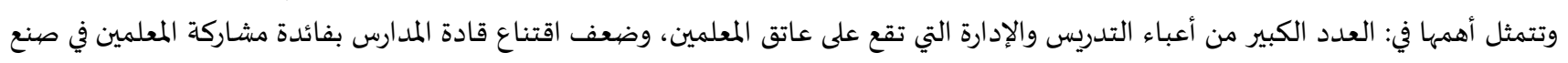


القرار (طيفور، 2020)، وكبر حجم المؤسسة، وحرص القائد على الاحتفاظ بالسلطة، وكثرة المهام التدريسية والإدارية، وقلة وجود الكفاءات والمؤهلات،

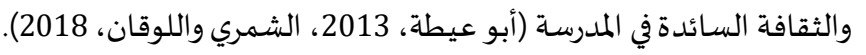
ويرتكز نجاح القيادة التشاركية على القائد التربوي الذي يتحلى بصفات تربوية منها الثقافة التي يمتلكها القائد؛ لما لها من تأثير في بناء شخصية

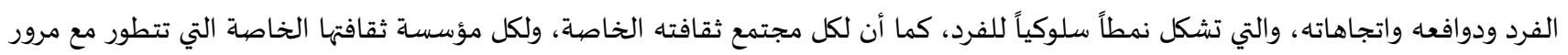
الوقت، فهي ظاهرة خاصية بالإنسان لها أهمية في التأثير على سلوك الأفراد العاملين (حريم ،

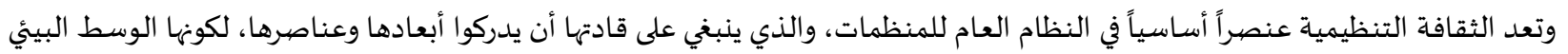

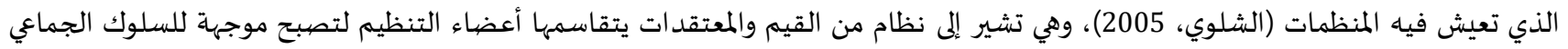

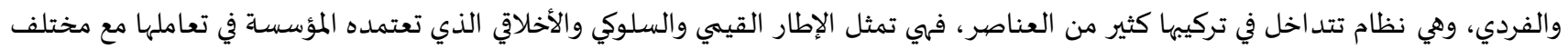

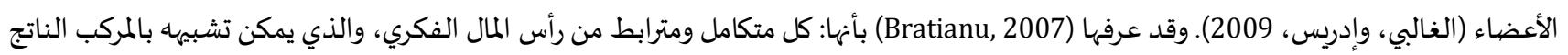
من مزج عنصرين أو أكثر من أجل الحصول على هوية جديدة تستند إلى التآزر والمشاركة (Kosar\&yalcinkaya,2013). وعرفها المرسي (2006) بأهها:

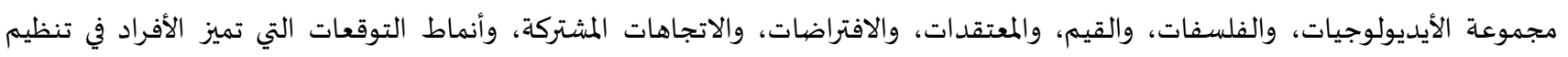

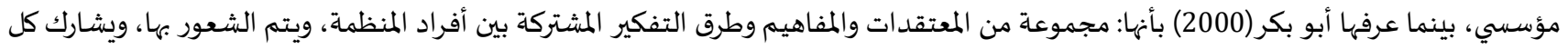

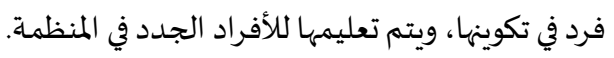

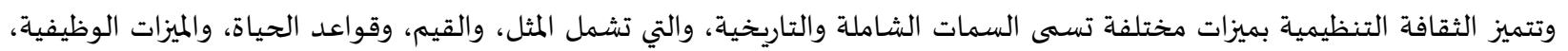

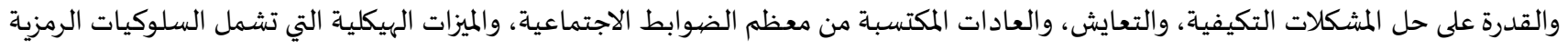

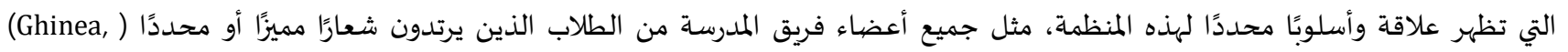
.Mihaylova\&Papazov,2015 وقد ازداد الاهتمام بالثقافة التنظيمية نتيجةً لزيادة المعرفة بمكوناتها وتأثيرها على عمل المنظمة، فهي الروح في جسم المنظمة، حيث أن جميع الأنشطة الحيوية التي تؤديها متجذرة في ثقافة المنظمة، كما أن مستقبل الإدارة في جميع المنظمات اليوم مرتبط بثقافته التنظيمية ( 2016 ،

(szymanska وتؤدي الثقافة التنظيمية عدة وظائف للمنظمات الإدارية تؤثر في مخرجاتها سلباً أو إيجاباً على شعور العاملين والقادة بالرضا والتعاون

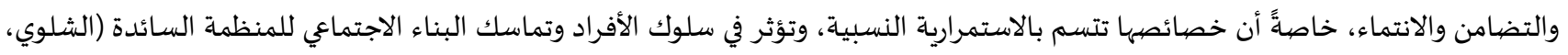

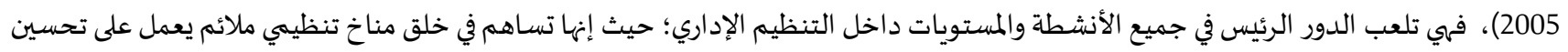

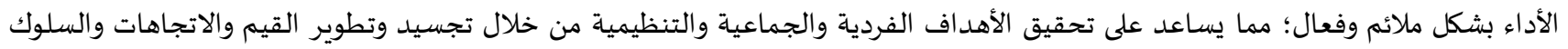

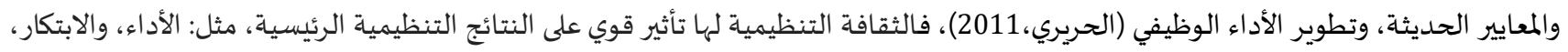

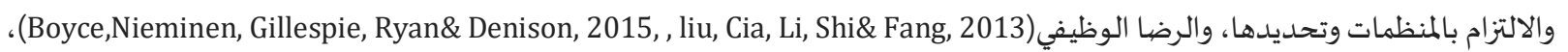

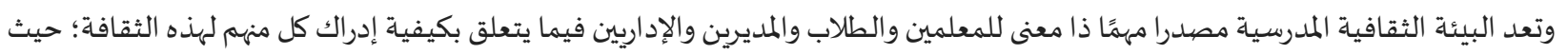
تعمل الثقافة التنظيمية للمدرسة كبوصلة للموظفين للعمل بشكل جماعي من خلال وضع القواعد المتعلقة بالتزامات العاملين في المدرسة

(Sergiovanni, 2000) وترتبط الثقافة التنظيمية بشكل وثيق بالقيادة التشاركية والإبداعية؛ حيث يؤكد (Trice\& Beyer, 1993, Schein, 2010) على أن أحد أهم

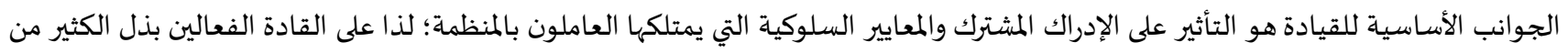

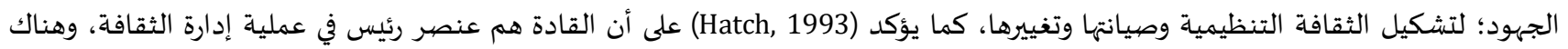

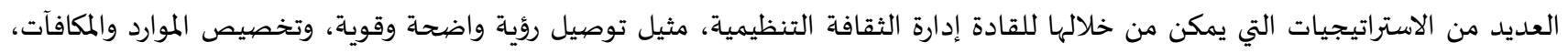

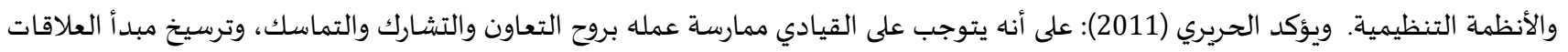

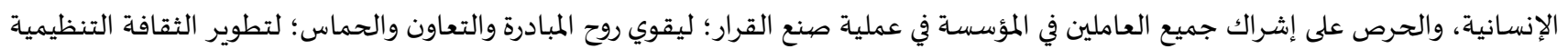

وبلورتها.

الدراسـات السـابقة: وقد أجريت العديد من الدراسات حول متغيرات الدراسةة،

• فقد هدفت دراسة (Mintari, Said Musnadi, Abd. Majid, 2020) إلى قياس وتحليل الآثار الوسيطة لأداء الموظف على آثار أسلوب القيادة التشاركية والمشاركة في العمل، وتعويض الأداء التنظيمي لمؤسسة Kotaku في إندونيسيا، وتم تطبيق الدراسة على عينة تكونت من (140) من 
موظفي الشركة، وكشفت الدراسة عن أن لأسلوب القيادة التشاركية، والمشاركة في العمل، وأثر التعويض نتائج إيجابية وهامة على أداء الموظف، الماركا.

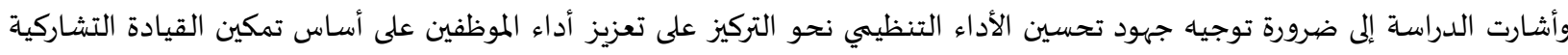

والمشاركة الوظيفية.

• وقامت طيفور (2020) بدراسة للكشف عن درجة تعرف قادة المدارس في محافظة عجلون للقيادة التشاركية، وتحديد معوقاتها، وتقديم

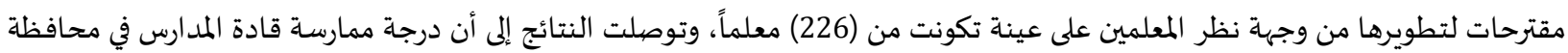

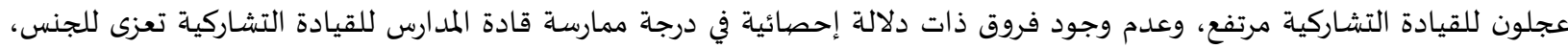
والمستوى المدرسي، وتجربة التدريس.

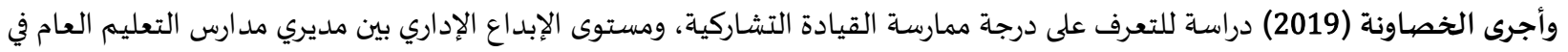

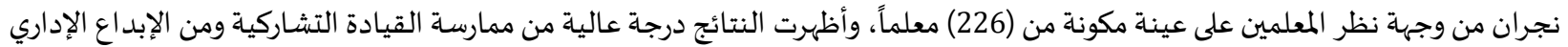

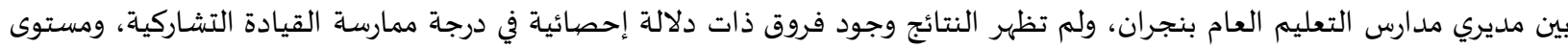
الإبداع الإداري تعزى للجنس والمؤهلات الأكاديمية والخبرة التعليمياة.

وهدفت دراسة الليمون (2019) الكشف عن درجة ممارسة القيادة التحويلية من قبل مديري المدارس الثانوية في الأردن وعلاقتها بالثقافة

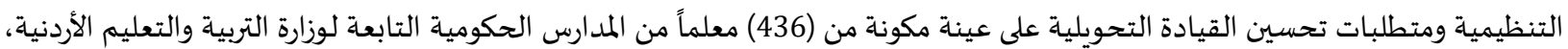

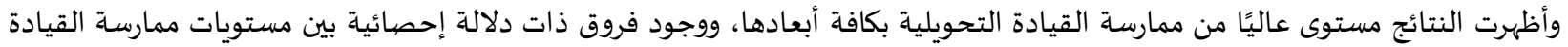

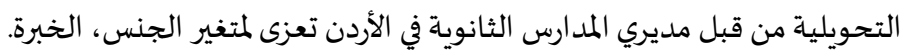
وقام العنزي (2019) بدراسة لتحديد مستوى الثقافة التنظيمية بين مديري ومعلمي المدارس المتوسطة والثانوية في مدينة عرعر على عينة

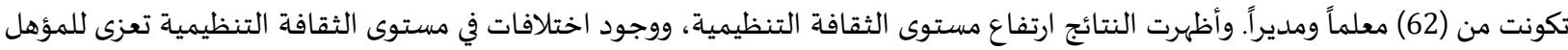
الأكاديمي لصالح البكالوريوس، ولسنوات الخبرة الخبرة لصالح (نطاق الخبرة 5-10). وقام درويش (2019) بدراسة لتحديد درجة ممارسة قائدات المدارس الثانوية بمحافظة الخرج للقيادة التشاركية وعلاقتها باتخاذ القرار من

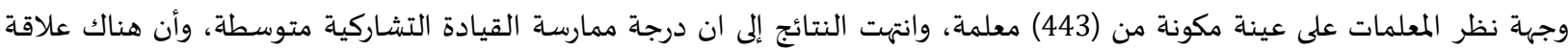

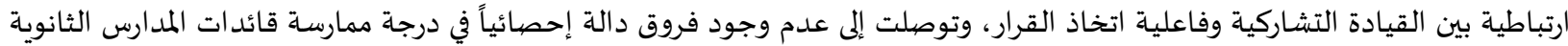
بمحافظة الخرج في القيادة التشاركية تعزى للمؤهل العلمي، ووجود فروق تعزى للتخصص والتبادية التبرة التدريسية.

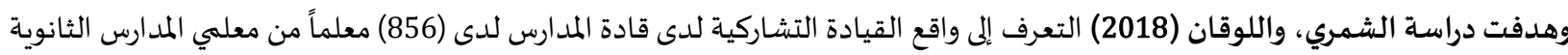

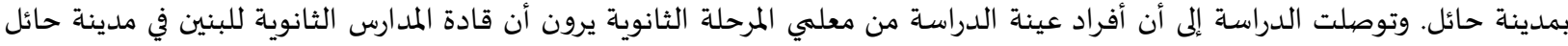

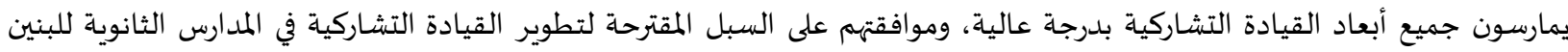
بمدينة حائل. وقام (Desselle, Raja, Andrews\& Lui, 2018) بدراسة لفحص العلاقة بين الثقافة التنظيمية وسلوكيات المواطنة التنظيمية على عينة

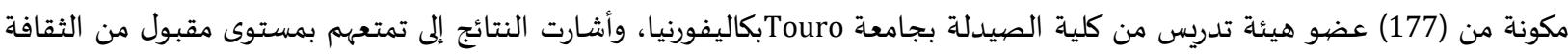
التنظيمية، ووجود علاقة ارتباطية إيجابية بين الثقافة التنظيمية وسلوكيات المواطنة التنظيمية. وأجرى (Chipunza \& Malo, 2017) دراسة هدفت تحديد العلاقة بين الثقافة التنظيمية، والرضا الوظيفي على عينة تكونت من (230) اكاديمياً بجامعة جنوب أفريقيا للتكنولوجيا، وانتهت النتائج إلى أن المعلمين لديهم توجهات وإدراكات إيجابية نحو الثقافة التنظيمية، ووجود علاقة الثانة ارتباطية بين الثقافة التنظيمية والرضا الوظيفي.

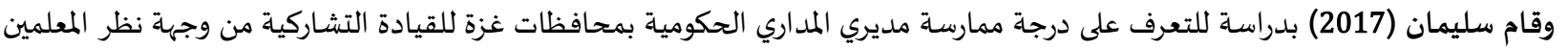

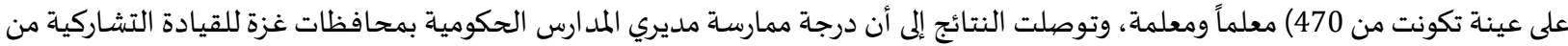

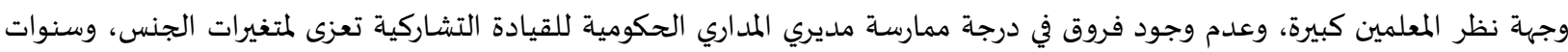
الخدمة والمؤهل العلمي. وأجرى المطيري (2015) دراسة للكشف عن درجة ممارسة مديري المدارس للمرحلة الثانوية للقيادة التشاركية في منطقة حفر الباطن وعلاقهها بالولاء التنظيمي، وانتهت النتائج إلى وجود علاقة ارتباطية بين القيادة التشاركية ومستوى الولاء التنظيمي. 
وهدفت دراسـة(Efanga\& Ifejiagwa, 2014) إلى الكشف عن العلاقة بين مكونات الثقافة التنظيمية وإدارة الأداء لمديري المدارس الثانوية في نيجيريا، وتكونت عينة الدراسة من (137) معلماً، وأشارت نتائج الدراسة إلى وجود علاقة دالة إحصائياً بين إدراك المعلمين لدرجة الثقافة

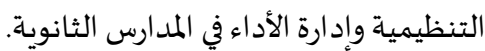

وأجرى عسكر (2012) دراسة هدفت فحص العلاقة بين القيادة التشاركية والثقافة التنظيمية لدى مديري المدارس الحكومية بمحافظات غزة من وجهات نظر المعلمين على (727) معلماً ومعلمة، وتوصلت الدراسة إلى أن درجة ممارسـة القيادة التشاركية عالية، بينما كان مستوى الثقافية

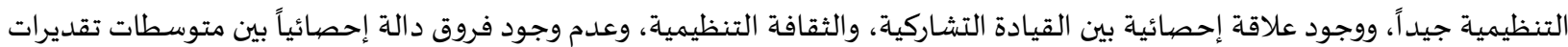

المعلمين لممارسة القيادة التشاركية تعزى لمتغير الجنس والمؤهل العلمي في المجال الأول والثاني.

وهدفت دراسة (Huang, Iun, Liu, Gong, 2010) التعرف إلى علاقة النمط القيادي التشاركي بتحسين أداء العمل من خلال عملية التمكين على عينة مكونة من (527) من موظفي شركة الاتصالات بالصين، وتوصلت النتائج إلى أن القيادة التشاركية تؤثر على أداء العمل وسلوك منك

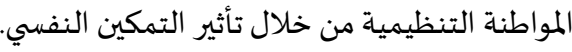
وقام الليثي (2008) بدراسة هدفت تحديد علاقة الثقافة التنظيمية بالإبداع الإداري لدى مديري المدارس الابتدائية على (115) مديراً، وتوصلت الدراسة إلى أن درجة ممارسة الثقافة السائدة كبيره جداً، كما توصلت إلى وجود فروق ذات دلالة إحصائية في الثقافة التنظيمية تعزى لمتغير المؤهل العلمي. وقام العجمي (2007) بدراسة للتعرف على درجة استخدام مديري المدارس الثانوية في دولة الكويت لنمط الإدارة التشاركية عند ليكرت من وجهة نظر المعلمين على (910) معلماً ومعلماة، وقد توصلت الدراسـة أن درجة استخدام المدراء لنمط الإدارة التشاركية عالية، ووجود فروق ذات دلالة إحصائية في نمط الإدارة تعزى للجنس لصالح الإناث في بإستثناء المجال الإداري، وللمؤهل لصائح الصالح حملة البكالوريوس. يتضح من العرض السابق للدراسات السابقة أهها أكدت على أهمية وتأثير القيادة التشاركية والثقافة التنظيمية، وأكدت على أهمية بناء ثقافة تنظيمية قادرة على الارتقاء بالعمل وتطويره وتجوديه من خلال القيادة التشاركية، كما أشارت لمستويات مقبولة لدى عيناتها في مستوى القيادة التشاركية والثقافة التنظيمية، وقد تشابهت مع الدراسة الحالية موضيوعها، ومنهجها، واستفادت منها الدراسة الحالية في صياغة مشكلتها وأسئلتها وفرضياتها، وبناء أدواتها، وتحليل نتائجها ومناقشتها. كما يتضح أهمية الدور القيادي التشاركي للتأثير على الأفراد؛ من أجل توجياء طاقاتهم لإنجاز العمل، كما يتضح أهمية وجود ثقافة تنظيمية تسمح بتحقيق أهداف المؤسسة، وتطوير خططها واستراتيجياتها؛ وصولاً للنجاح المنشود، ومن هنا اتجهت الدراسة الحالية لدراسة القيادة التشاركية

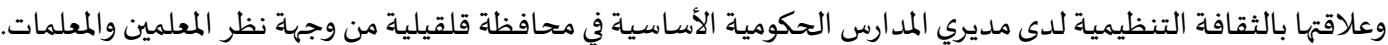

مشكلة الدراسـة: نظراً لأهمية الدور القيادي الذي يمثله مدير المدرسة؛؛ لكونه يمثل أعلى سلطة في المدرسة، وهو الملكلف بمهام كثيرة إدارية وفنية وتطويرية، تتطلب مناه متابعة نمو المدرسة، والارتقاء بالعملية التعليمية فيها من خلال رفع مستوى تحصيل الطلبة، وبناء مهاراتهم الشخصية؛ لتحقيق النمو

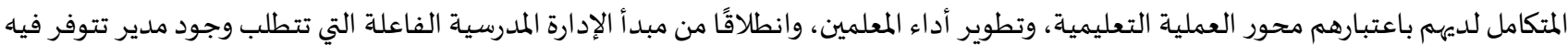
المهارات الإدارية والمهارات القيادية تؤهله لتحقيق رؤية تطويرية للمدرسة، وانطلاقاً من الضرورة الملحة التي تدفع بالقيادة المدرسية أن تكون قيادة

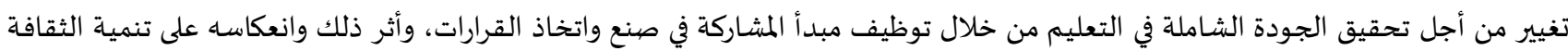
التنظيمية، فقد تحددت مشكلة الدراسة في: القيادة التشاركية وعلاقتها بالثقافة التنظيمية لدى مديري المدارس الحكومية الأسـاسية في محافظة قلقيلية من وجهة نظر المعلمين والمعلمات.

أسئلة الدراسـة:

سعت الدراسة للإجابة عن الأسئلة الرئيسة التالية: 1. ما درجة ممارسة مديري المدراس الحكومية الأساسية في محافظة قلقيلية للقيادة التشاركية من وجهة نظر المعلمين والمعلمات؟

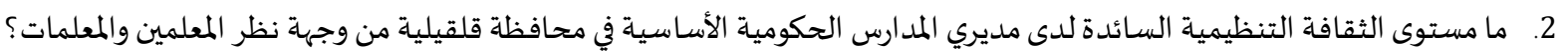
3. هل توجد علاقة ارتباطية دالة إحصائياً في درجة ممارسة مديري المدراس الحكومية الأساسية في محافظة قلقيلية للقيادة التشاركية ومستوى من منهية الثقافة التنظيمية السائدة لديهم من وجهاة نظر المعلمين والمعلمات 4. هل توجد فروق في درجة ممارسة مديري المدراس الحكومية الأسـاسية في محافظة قلقيلية للقيادة التشاركية من وجهة نظر المعلمين والمعلمات تعزى لمتغير الجنس، وسنوات الخبرة، والمؤهل العلمي؟ 
5. هل توجد فروق في درجة ممارسة مديري المدراس الحكومية الأساسية في محافظة قلقيلية للثقافة التنظيمية السائدة من وجهة نظر المعلمين

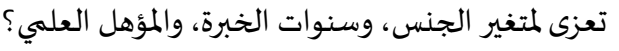

فرضيات الدراسة:

1. لا توجد علاقة ارتباطية ذات دلالة إحصائية (م=0.05) في درجة ممارسة مديري المدراس الحكومية الأساسية في محافظة قلقيلية للقيادة

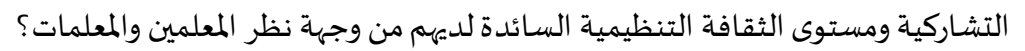

2. لا توجد فروق ذات دلالة إحصائية (م=0.05) في درجة ممارسـة مديري المدراس الحكومية الأسـاسية في محافظة قلقيلية للقيادة التشاركية من

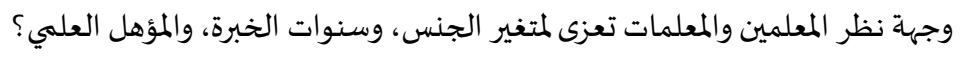

3. لا توجد فروق ذات دلالة إحصائية (م=0.05) في درجة ممارسة مديري المدراس الحكومية الأساسية في محافظة قلقيلية للثقافة التنظيمية

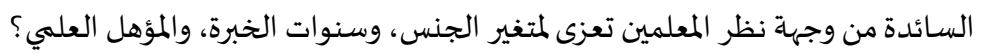

أهداف الدراسة:

تتمثل أهداف الدراسة بما يلي:

1. التعرف إلى درجة ممارسة مديري المدراس الحكومية الأساسية في محافظة قلقيلية للقيادة التشاركية من وجهة نظر المعلمين والمعلمات.

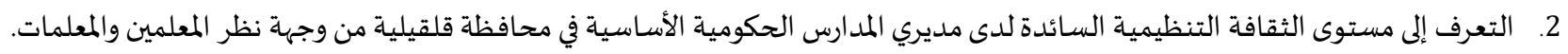
3. التعرف إلى طبيعة العلاقة بين درجة ممارسة مديري المدراس الحكومية الأساسية في محافظة قلقيلية للقيادة التشاركية ومستوى الثقافة مدية

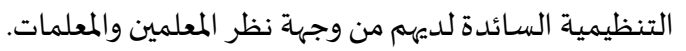

4. التعرف إلى طبيعة العلاقة بين ممارسة مديري المدراس الحكومية الأساسية في محافظة قلقيلية للقيادة التشاركية ومستوى الثقافة التنظيمية السائدة لديهم من وجهة نظر المعلمين والمعلمات

5. تحديد طبيعة الفروق في درجة ممارسة مديري المدراس الحكومية الأساسية في محافظة قلقيلية للثقافة التنظيمية من وجهة نظر المعات المعلمين

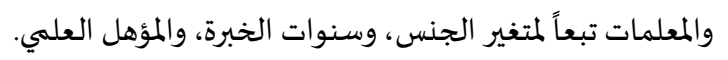

أهمية الدراسـة:

الأهمية النظرية: تستمد هذه الدراسـة أهميتها من:

1. أهمية موضهوعها المتعلق بالقيادة التشاركية وعلاقتها بالثقافة التنظيمية؛ حيث إنها مدخل لعدية العلاج كثير من المشكلات المهنية التي يواجهها المعلمون، ويسعى لتعزيز الثقة المتبادلة بين القادة التربويين ومرؤوسيهم، وما يترتب على ذلك من مواكبة للمستجدات المهات العلمية والتربوية من خلال

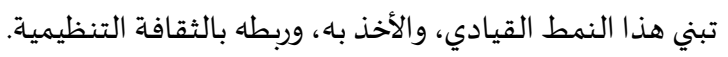
2. تُعد من الدراسات البحثية الأولى التي تناولت موضون بدوع القيادة التشاركية وعلاقتها بالثقافة التنظيمية لدى مديري المدارس الحكومية الأساسية في

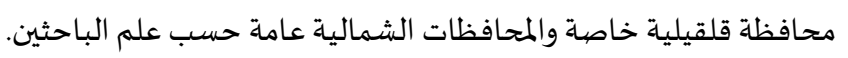
3. إثراء المكتبات الجامعية في فلسطين خاصيةً، ومواقع المكتبات الجامعية الإلكترونية عامة بالمادة البحثية والعادية الماتمية المتعلقة بالقيادة التشاركية

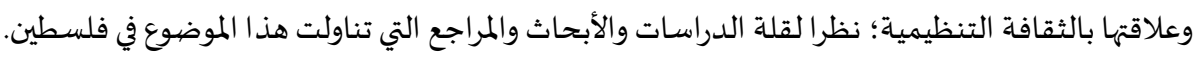

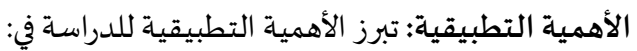
1. توجياء أنظار المهتمين من متخذي القرار في وزارة التربية والتعليم لأهمية ممارسة القيادة التشاركية في المدارس الحكومية، والتعرف إلى واقع

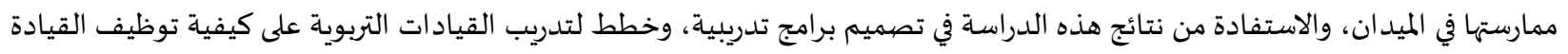
التشاركية، ونشر ثقافة تنظيمية تساهم في تطوير المؤسسة التعليمية.

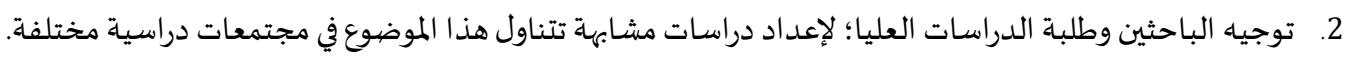

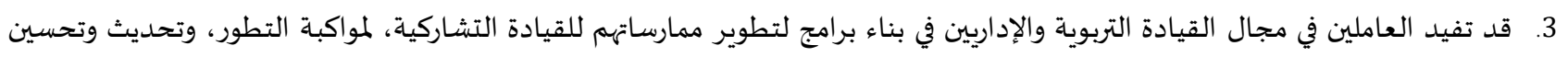
العمل التربوي والتعليمي ضمن الثقافة التنظيمية المبتكرة. 
تتحدد الدراسـة الحالية بموضوعها المتمثل في درجة ممارسة القيادة التشاركية وعلاقتها بالثقافة التنظيمية لدى مديري المدارس الحكومية الأساسية في محافظة قلقيلية من وجهات نظر المعلمين والمعلمات، وبعينتها المكونة من (140) من معلمي المدارس الحكومية في محافظة قلقيلية، وبأدواتها المتمثلة في مقياس القيادة التشاركية، ومقياس الثقافة التنظيمية، وبالأساليب الإحصائية المستخدمة في تحليل نتائج الدراسـة.

مصطلحات الدراسـة: القيادة التشـاركية: يعرفها الباحثان إجرائياً بأنها: أحدد الأنماط القيادية التي يمارسها القائد الإداري، والتي تهتم بتفويض الصلاحيات للمعلمين والمعلمات،

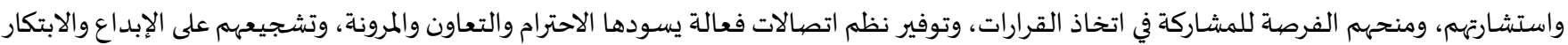
بما يساهم في الارتقاء بالعمل وتجويده. الثقافة التنظيمية: يعرفها الباحثان إجرائياً بأها: نظام من القيم والمعتقدات والافتراضات المشتركة بين أفراد المنظمة؛ للحصيول على هوية مستندة للمشاركة والتوافق ضمن البيئة الإنسانية التي يعمل فيها الموظف.

إجراءات الدراسـة: منهج الدراسة:

استخدمت الدراسة المنهج الوصفي الذي تحاول الدراسة من خلاله تحديد العلاقة بين القيادة التشاركية والثقافة التنظيمية لدى مديري المدارس الحكومية الأساسية في محافظة قلقيلية من وجهة نظر المعلمين والمعلمات. مجتمع الدراسة:

تكون مجتمع دراسة من جميع المعلمين والمعلمات، والبالغ عددهم (621) معلماً ومعلمة في المدارس الحكومية الأساسية في مديرية قلقيلية.

عينة الدراسة:

تكونت عينة الدراسـة من (140) معلماً ومعلمة تم اختيارهم بشكل عشوائي من المدارس الحكومية الأساسية في مديرية قلقيلية، وجدول (1) يبين توزيع عينة الدراسة من المعلمين والمعلمات وفقاً لمتغيرات الدراسة. جدول (1): يوضح توزيع عينة الدراسة من المعلمين والمعلمات وفقاً لمتغيرات الدراسة

\begin{tabular}{|c|c|c|c|}
\hline النسبة المئوية \% & العدد & مستويات المتغير & المتغير \\
\hline 51.43 & 72 & ذكر & الجنس \\
\hline 48.57 & 68 & أنثى & \\
\hline$\% 100$ & 140 & المجموع & \\
\hline 23.6 & 33 & اقل من 5 سنوات & سنوات الخبرة \\
\hline 21.4 & 30 & من 5-10 سنوات & \\
\hline 55.0 & 77 & أكثر من 10 سنوات & \\
\hline$\% 100$ & 140 & المجموع & \\
\hline 5.7 & 8 & دبلوم - & المؤهل العلهي \\
\hline 79.3 & 111 & بكالوريوس & \\
\hline 15 & 21 & ماجستير فأعلى & \\
\hline$\% 100$ & 140 & المجموع & \\
\hline
\end{tabular}

أدوات الدراسـة:

استخدمت الدراسة المقاييس التالية: أولاً: مقياس القيادة التشاركية:

وصف المقياس: تم إعداد المقياس بعد الرجوع للأدب التربوي والدراسات السابقة ذات العلاقة ومنها دراسة درويش (2019)، ودراسة الشمري، واللوقان (2018)، وتكون المقياس في صورته النهائية من (23) فقرة، موزعة على ثلاثة مجالات، هي:

المشاركة في اتخاذ القرار:وتشتمل على الفقرات (1-8).

تفويض السلطة: وتشتمل على الفقرات (9-14). 
العلاقات الإنسانية: وتشتمل على الفقرات (15-23).

ويجيب المعلم من خلال تدريج مكون من خمس خيارات، هي: موافق بشدة، موافق، محايد، أعارض، أعارض بشـدة، وذلك بوضع علامة أمام

الإجابة التي تنطبق عليه.

صدق المقياس: تم التحقق من صدي المقياس بالطرق الآتية:

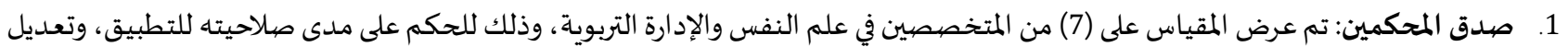

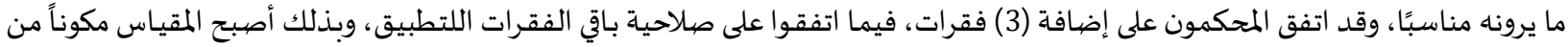

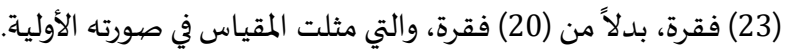
2. الصيدق البنائي: تم تطبيق القائمة على عينة استطلاعية عددها (30) من المعلمين من خارج عينة الدراسـة، وتم إيجاد معاملات الارتباط بين الدرجة الكلية لكل مجال مع الدرجة الكلية للمقياس، وجدول (2) يوضح ذلك:

\begin{tabular}{|c|c|c|}
\hline قيمة الدلالة & معامل الارتباط & المجال \\
\hline 0.00 & $* 0.83$ & الأول: المشاركة في اتخاذ القرار \\
\hline 0.00 & $* 0.96$ & الثاني: تفويض السلطة \\
\hline 0.00 & $* 0.92$ & الثالث: العلاقات الإنسـانية \\
\hline
\end{tabular}

يتضح من جدول (2) أن معاملات الارتباط مرتفعة ودالة، مما يؤكد على صهدق المقياس، وصلاحيته للتطبيق.

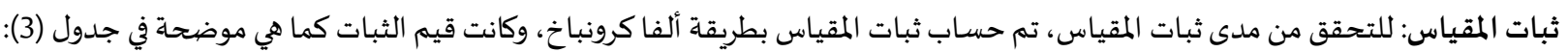
جدول (3): يبين الجدول معامل الثبات للدرجة الكلية و أبعاد مقياس القيادة التشاركية

\begin{tabular}{|c|c|c|c|}
\hline معامل الثبات & عدد الفقرات & المجال & الرقم \\
\hline 0.96 & 8 & المشاركة في اتخاذ القرار & 1 \\
\hline 0.84 & 6 & تفويض السلطة & 2 \\
\hline 0.91 & 9 & العلاقات الإنسانية & 3 \\
\hline 0.93 & 23 & الدرجة الكلية & \\
\hline
\end{tabular}

يتضح من جدول (3) أنَّ معاملات الثبات للدرجة الكلية ومجالات مقياس القيادة التشاركية مرتفعة؛ حيث بلغ معامل الثبات الكلي (0.93)، وتراوحت معاملات الثبات للمجالات بين (0.84-0.96)، وجميعها معاملات ثبات عالية تؤكد على صلاحية المقياس للتطبيق. ثانياً: مقياس الثقافة التنظيمية: وصفف المقياس: تم إعداد المقياس بعد الرجوع للأدب التربوي والدراسات السابقة ذات العلاقة، ومنها دراسة العنزي (2019)، ودراسة الليثي (2008)،

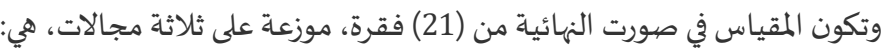
الهيكل التنظيمي: وتشتمل على الفقرات (1-5). أنظمة الحوافز: وتشتمل على الفقرات (6-11). العمليات: وتشتمل على الفقرات (12-12). ويجيب المعلم من خلال تدريج مكون من خمسـة خيارات، هي: موافق بشدة، موافق، محايد، أعارض، أعارض بشدة، وذلك بوضع علامة أمام الإجابة التي تنطبق عليه.

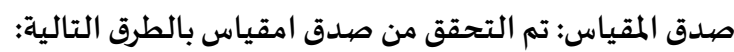

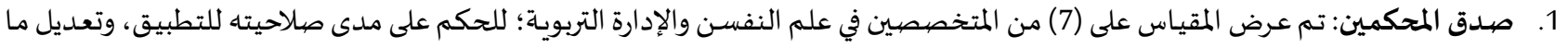
يرونه مناسبًا، وقد اتفق المحكمون على حذف (4) فقرات، فيما اتفقوا على صلاحية باقي الفقرات اللتطبيق، وبذلك أصفئ أصبح المقياس مكوناً من (21)

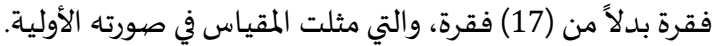
2. الصدق البنائي: تم تطبيق القائمة على عينة استطلاعية عددها (30) من المعلمين من خارج عينة الدراسة، وتم إيجاد معاملات الارتباط بين

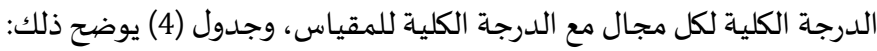


جدول (4): معاملات الارتباط بين الدرجة الكلية للمجال مع الدرجة الكلية لمقياس الثقافة التنظيمية

\begin{tabular}{|c|c|c|}
\hline قيمة الدلالة & معامل الارتباط & فقرات المجال \\
\hline 0.00 & $* 0.95$ & المجال الأول: الهيكل التنظيمي \\
\hline 0.00 & $* 0.96$ & المجال الثاني: أنظمة الحو افز \\
\hline 0.00 & $* 0.93$ & المجال الثالث: العمليات \\
\hline
\end{tabular}

يتضح من نتائج جدول (4) أن جميع معاملات ارتباط بيرسون بين الدرجة الكلية ومجالات مقياس الثقافة التنظيمية، والدرجة الكلية للمقياس ككل، دالة إحصائياً عند مستوى (0.01)؛ حيث تراوحت معاملات الارتباط بين (0.93-0.96)، وهي معاملات ارتباط مرتفعة ودالة؛ مما يؤكد على صدق المقياس، وصلاحيته للتطبيق.

ثبات المقياس: للتحقق من مدى ثبات المقياس، تم حساب ثبات المقياس بطريقة ألفا كرونباخ، وكانت قيم الثبات كما هي موضحة في جدول (5).

\begin{tabular}{|c|c|c|c|}
\hline معامل الثبات & عدد الفقرات & المجال & الرقم \\
\hline 0.82 & 5 & الهيكل التنظيهي & 1 \\
\hline 0.85 & 6 & أنظمة الحوافز & 2 \\
\hline 0.90 & 10 & العمليات & 3 \\
\hline 0.94 & 21 & الدرجة الكلية & \\
\hline
\end{tabular}

يتضح من جدول (5) أنَّ معاملات الثبات للدرجة الكلية لمقياس القيادة التشاركية وأبعاده مرتفعة؛ حيث بلغ معامل الثبات الكلي (0.94)، وتراوحت معاملات الثبات للمجالات بين (0.82-0.90)، وجميعها معاملات ثبات عالية تؤكد على صلاحية المقياس للتطبيق. الحكم على استجابات العينة:

اعتمدت الدراسة المقياس الآتي لتقدير درجة الممارسة للقيادة التشاركية ومستوى الثقافة التنظيمية اعتمادا على ما ذكرته الدراسـات السابقة، وعلى آراء المحكمين كالتالي:

$$
\text { المتمتوسط الحسابي (4.21 فأكثر) يشير إلى درجة مرتفعة جداً. }
$$

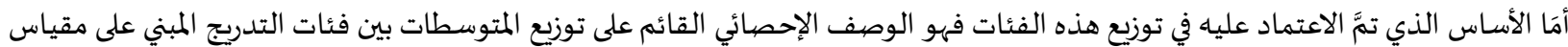

ليكرت الخماسي، والذي يبدأ من أوافق بشدة (5) درجات، أوافق (4) درجات، محايد (3)، معارض (2)، معارض بشدة (1).

$$
\text { نتائج الدراسة ومناقشتها: }
$$

\begin{tabular}{|c|c|c|c|c|c|}
\hline \multicolumn{4}{|c|}{ المعلمون } & \multirow[t]{3}{*}{ المجال } & \multirow[t]{3}{*}{ رقم المجال } \\
\hline النسبة المئوية & الدرجة & الانحراف & المتوسط & & \\
\hline & & المعياري & الحسابي & & \\
\hline$\% 76.2$ & مرتفعة & 0.53 & 3.81 & المشاركة في اتخاذ القرار & 1 \\
\hline$\% 78.6$ & مرتفعة & 0.64 & 3.93 & تفويض السلطة & 2 \\
\hline$\% 77.6$ & مرتفعة مرت & 0.68 & 3.88 & العلاقات الإنسانية & 3 \\
\hline$\% 77.4$ & مرتفعة & 0.56 & 3.87 & الدرجة الكلية & 4 \\
\hline
\end{tabular}

إجابة السؤال الأول والذي ينص على "ما درجة ممارسة مديري المدراس الحكومية الأسـسية في محافظة قلقيلية للقيادة التشاركية من وجهات نظر المعلمين والمعلمات؟

ولإجابة عن السؤال السابق تمّ استخراج المتوسطات الحسابية والانحرافات المعيارية لدرجة ممارسة مديري المدراس الحكومية الأسـاسية في محافظة قلقيلية للقيادة التشاركية من وجهات نظر المعلمين والمعلمات، وجدول (6) يوضح ذلك. 
يتضح من جدول (6) أنَّ مستوى القيادة التشاركية لدى مديري المدارس الحكومية الأسـاسية في محافظة قلقيلية من وجهات نظر المعلمين والمعلمات جاء بدرجة مرتفعة؛ حيث بلغ المتوسط الحسابي للدرجة الكلية (3.87)، وبنسبة مئوية قدرها (77.4\%) من المعلمين والذين أفادوا بأن

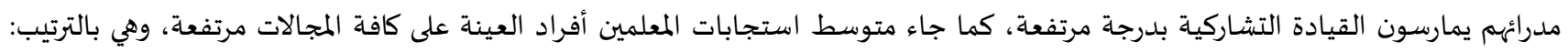

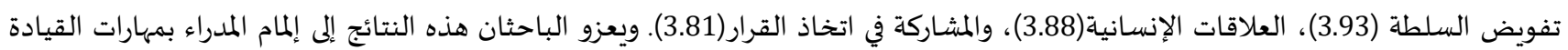

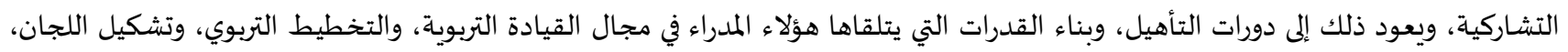
وتوزيع الأدوار، وتفويض السلطة، وبناء العلاقات الإنسانية، وههارات الاتصال والتواصل من خلال المعهد الوطني للتدريب التابع لوزارة التربية

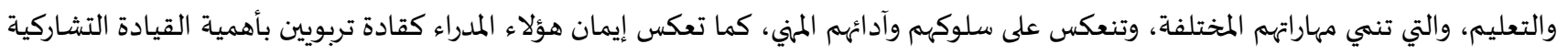

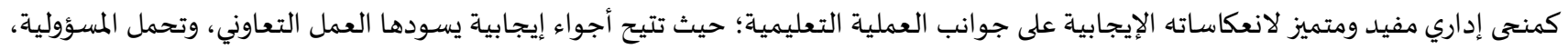

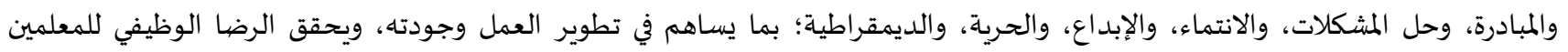

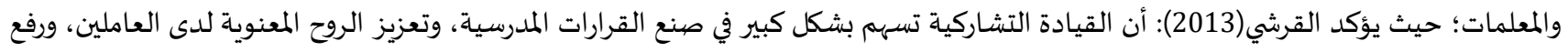

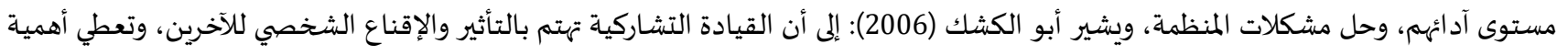

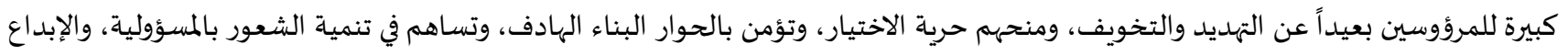

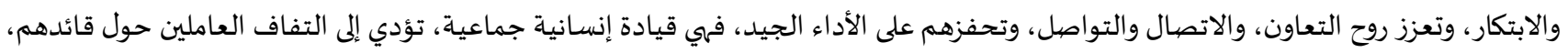

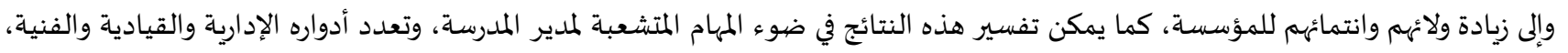

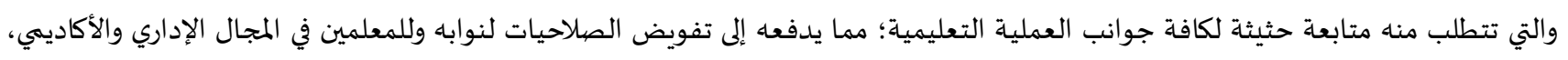

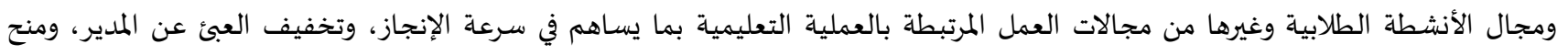

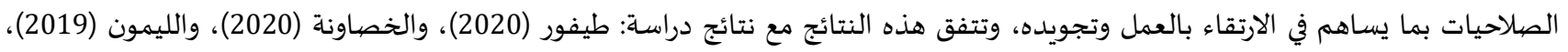

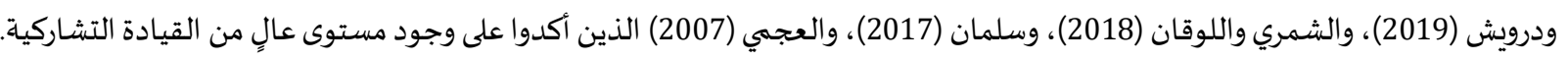
إجابة السؤال الثاني والذي ينص على "ما مستوى الثقافة التنظيمية السـائدة لدى مديري المدارس الحكومية الأسساسية في محافظة قلقيلية من وجهات نظر المعلمين والمعلمات؟

للإجابة عن السؤال، تم استخراج المتوسطات الحسابية والانحرافات المعيارية لدرجة ممارساة مديري المدراس الحكومية الأسـاسية في محافظة

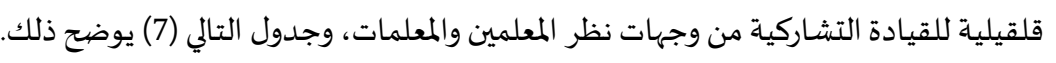

جدول (7): يوضيح المتوسطات الحسابية والانحر افات المعيارية لمستوى الثقافة التنظيمية السائدة لدى مديري المدارس من وجهات نظر المعلمين والمعلمات

\begin{tabular}{|c|c|c|c|c|c|}
\hline \multicolumn{4}{|c|}{ المعلمون } & \multirow[t]{2}{*}{ 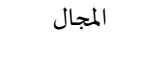 } & \multirow{2}{*}{ رقمال } \\
\hline النسبة المئوية\%\% & الدرجة & الانحراف المعياري & المتوسط الحسابي & & \\
\hline 77.2 & مرتفعة & 0.64 & 3.86 & الهيكل التنظيمي & 1 \\
\hline 78.6 & مرتفعة & 0.64 & 3.93 & أنظمة الحوافز & 2 \\
\hline 80.00 & مرتفعة & 0.58 & 4.00 & العمليات & 3 \\
\hline 78.6 & مرتفعة & 0.59 & 3.93 & الدرجة الكلية & 4 \\
\hline
\end{tabular}

يتضح من جدول (7) أنَّ مستوى الثقافة التنظيمية السائدة لدى مديري المدارس الحكومية الأساسية في محافظة قلقيلية من وجهات نظر

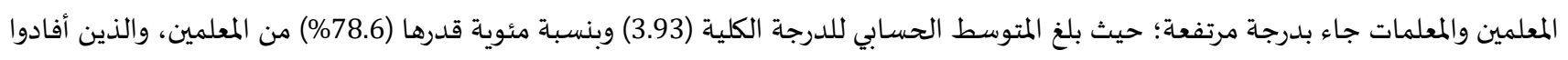

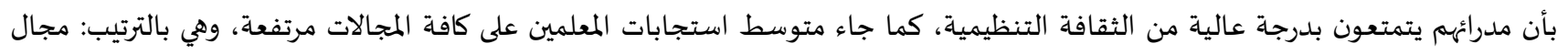

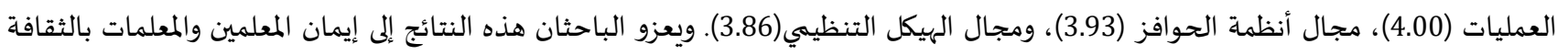

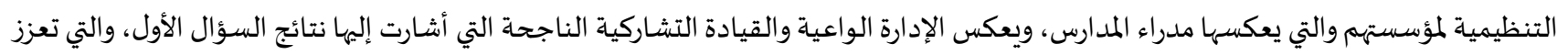

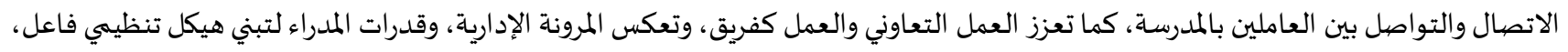

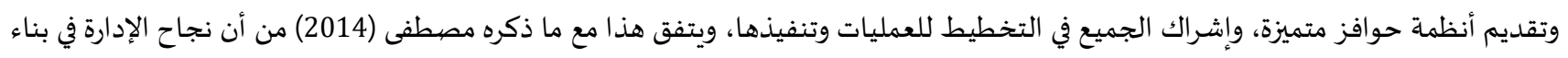
ثقافة تنظيمية إيجابية، يساعدها في حسن تكييف المنظمة مع المتغيرات البيئية، وفي الاستمرار والبقاء، وتكوين رؤية متكاملة ومشتركة بين ألماتئ أعضاء

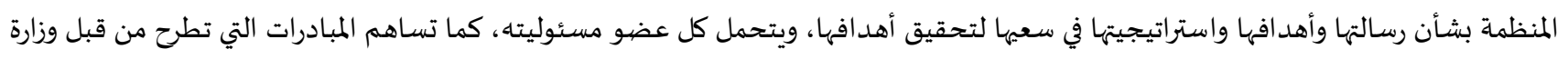

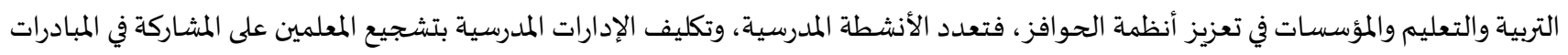

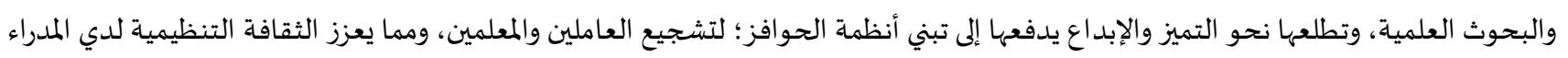

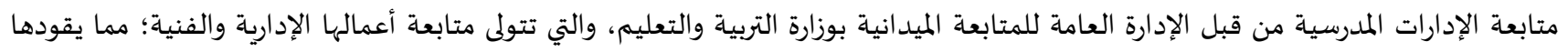

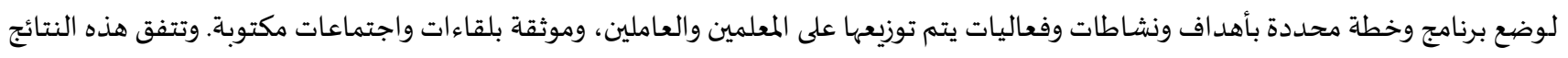


مع دراستي العنزي (2019)، والليثي (2008) اللذين توصلا إلى وجود مستوى عال من الثقافة التنظيمية، ودراسة،، Desselle, Raja, Andrews\& Lui, (2018 التي أشـارت إلى تمتع أفراد عينة الدراسة بمستوى مقبول من الثقافة التنظيمية، ودراسة (Chipunza \& Malo, 2017) التي انتهت النتائج إلى أن

المعلمين لديهم توجهات وإدراكات إيجابية نحو الثقافة التنظيمية. إجابة السؤال الثالث والفرض الخاص به والذي ينص على "لا توجد علاقة ارتباطية ذات دلالة إحصائية (X=0.05) في درجة ممارسة مديري المدراس الحكومية الأسـاسية في محافظة قلقيلية للقيادة التشاركية ومستوى الثقافة التنظيمية السائدة لديهم من وجهة نظر المعلمين

ولفحص الفرض السـابق تم استخدام معامل ارتباط بيرسون في للكشف عن طبيعة العلاقة بين ممارسة مديري المدراس الحكومية الأساسية في محافظة قلقيلية للقيادة التشاركية ومستوى الثقافة التنظيمية السائدة لديهم من وجهة نظر المعلمين والمعلمات، وكانت النتائج كما يوضحها جدول

\begin{tabular}{|c|c|c|c|c|c|}
\hline \multirow[t]{2}{*}{ مستوى الدلالة } & \multirow[t]{2}{*}{ معامل الارتباط } & \multicolumn{2}{|c|}{ الثقافة التنظيمية } & \multicolumn{2}{|c|}{ القيادة التشاركية } \\
\hline & & الانحراف & الوسط الحسابي & الانحراف & الوسط الحسابي \\
\hline \multirow[t]{2}{*}{0.000} & ${ }^{* *} 0.848$ & المعياري & & المعياري & \\
\hline & & 0.59 & 3.93 & 0.56 & 3.87 \\
\hline
\end{tabular}

يتضح من جدول (8) وجود علاقة ارتباطية ذات دلالة إحصائية عند مستوى الدلالة (ل0.05) بين الدرجة الكلية لمقياس القيادة التشاركية والدرجة الكلية لمقياس الثقافة التنظيمية السائدة لدى مديري المدارس الحكومية الأسـاسية في قلقيلية من وجهات نظر المعلميات داتين والمعلمات بمعامل ارتباط مقداره (0.848). ويعزو الباحثان هذه النتيجة إلى الدور القيادي للإدارة المدرسية والذي يؤثر بطريقة إيجابية أو سلبية على الثقافة التنظيمية

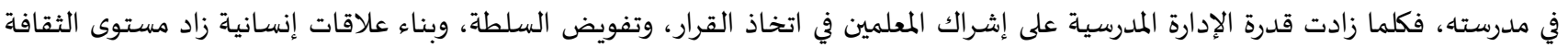
التنظيمية المتمثل في بناء مخطط وهيكل تنظيمي، وإدارة العمليات، واستخد ام أنظمة حوافز بشكل ناجح، فالقادة التربويون لديهم القدرة الكافية على

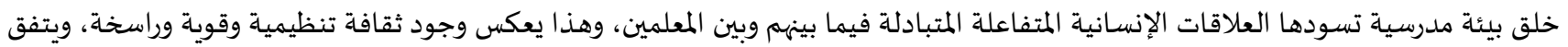
هذا مع ما ذكرته (الحريري، 2011 ) والتي أكدت على أن الثقافة التنظيمية ترتبط بشكل وثيق بالإدارة التشاركية التي توجب على مدير المدرسة كقائد

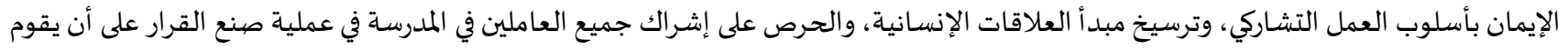

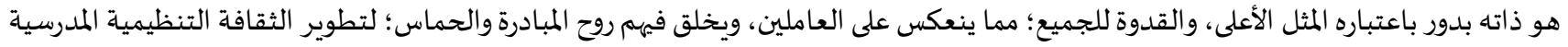

وبلورتها ودعمها. وتتفق هذه النتائج مع نتائج دراسـة عسكر (2012) التي أكدت على وجود علاقة ارتباطية بين القيادة التشاركية والثقافة التنظيمياة. إجابة السؤال الر ابع والفرض الخاص به والذي ينص على "لا توجد فروق ذات دلالة إحصائية (م=0.05) في درجة ممارسة مديري المدراس الحكومية الأساسية في محافظة قلقيلية للقيادة التشاركية من وجهة نظر المعلمين والمعلمات تعزى لمتغير الجنس، وسنوات الحسية الخبرة، والمؤهل العلمي" ولفحص الفرض السابق استخدمت الدراسة اختبار "ت" لمجموعتين مستقلتين، واختبار تحليل التباين الأحادي(One-way ANOVA)، وقد تم عرض نتائج كل متغير على حدة على النحو التالي:

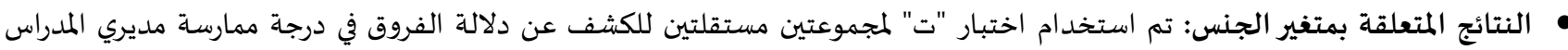

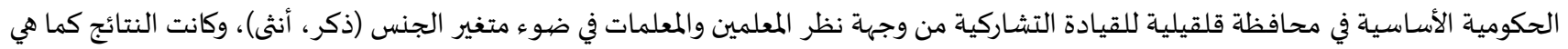
موضحة في جدول (9).

\begin{tabular}{|c|c|c|c|c|c|c|}
\hline \multirow[t]{2}{*}{ الدلالة } & \multirow[t]{2}{*}{ قيمة (ت) } & \multicolumn{2}{|c|}{ أنثى (ن =68) } & \multicolumn{2}{|c|}{ ذكر(ن=72) } & \multirow[t]{2}{*}{ المجال } \\
\hline & & الانحراف & المتوسط & الانحراف & المتوسط & \\
\hline 0.16 & 1.41 & 0.54 & 3.75 & 0.52 & 3.88 & المشاركة في اتخاذ القرار \\
\hline 0.15 & 1.44 & 0.63 & 3.85 & 0.65 & 4.01 & تفويض السلطة \\
\hline$*_{0} 0.03$ & 2.14 & 0.74 & 3.76 & 0.62 & 4.01 & العلاقات الإنسانية \\
\hline 0.06 & 1.87 & 0.57 & 3.78 & 0.55 & 3.96 & الدرجة الكلية \\
\hline
\end{tabular}

يتضح مِن نتائج جدول(9) عدم وجود فروق ذات دلالة إحصائية عند مستوى الدلالة (م=0.05) بين متوسطات استجابات المعلمين في الدرجة

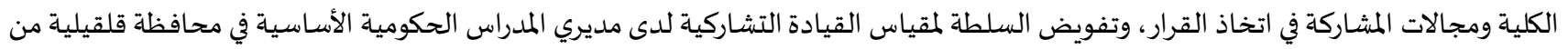


وجهات نظر المعلمين والمعلمات تعزى لمتغير الجنس، في حين وجدت فروق ذات دلالة إحصائية في مجال العلاقات الإنسانية لصالح المعلمين(الذكور)،

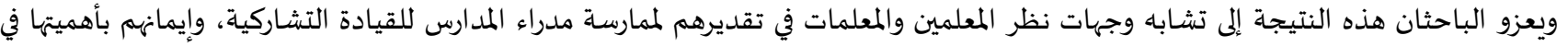

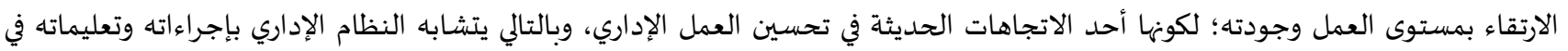

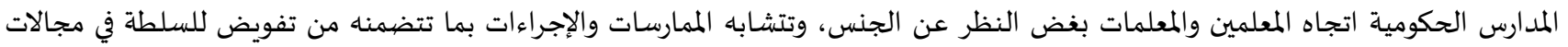

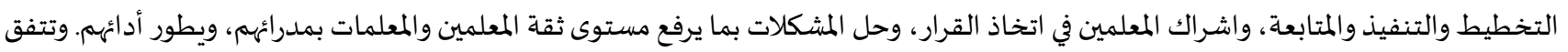

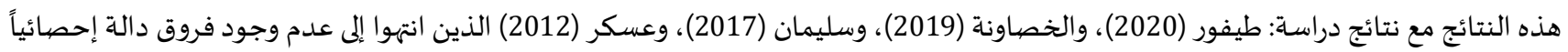

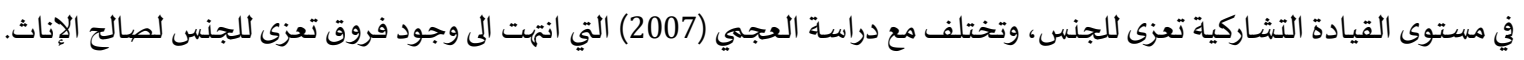

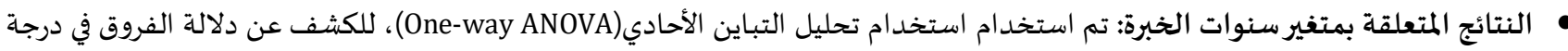

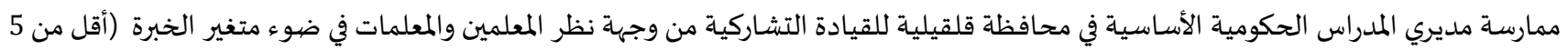
سنوات، من 5- 10 سنوات، أكثر من 10 سنوات سنوات)، وكانت المنتائج كما في جدول (10). جدول (10): نتائج تحليل التباين الأحادي لدلالة الفروق في درجة ممارسة مديري المدراس للقيادة التشاركية من وجهة نظر المعلمين والمعلمات في ضوء متغير

\begin{tabular}{|c|c|c|c|c|c|c|}
\hline \multicolumn{7}{|c|}{ سنوات الخبرة } \\
\hline الدلالة الإحصائية & قيمة(ف) & متوسط & درجات الحرية & مجموع المربعات & مصدر التباين & المجالات \\
\hline & & المربعات & & & & \\
\hline \multirow[t]{3}{*}{0.816} & 0.203 & 0.056 & 2 & 0.111 & بين المجموعات & المشاركة في اتخاذ القرار \\
\hline & & 0.273 & 137 & 37.424 & داخل المجموعات & \\
\hline & & & 139 & 37.535 & المجموع & \\
\hline \multirow[t]{3}{*}{0.920} & 0.083 & 0.034 & 2 & 0.067 & بين المجموعات & تفويض السلطة \\
\hline & & 0.404 & 137 & 55.300 & داخل المجموعات & \\
\hline & & & 139 & 55.367 & المجموع & \\
\hline \multirow[t]{3}{*}{0.668} & 0.404 & 0.187 & 2 & 0.375 & بين المجمموعات & العلاقات الإنسانية \\
\hline & & 0.463 & 137 & 63.473 & داخل المجموعات & \\
\hline & & & 139 & 63.848 & المجموع & \\
\hline \multirow[t]{3}{*}{0.879} & 0.129 & 0.039 & 2 & 0.078 & بين المجموعات & \\
\hline & & 0.303 & 137 & 41.554 & داخل المجموعات & الدرجة الكلية \\
\hline & & & 139 & 41.632 & المجموع & \\
\hline
\end{tabular}

يتضح من جدول (10) عدم وجود فروق ذات دلالة إحصائية عند مستوى الدلالة (م=0.05) بين متوسطات استجابات المعلمين للدرجة الكلية

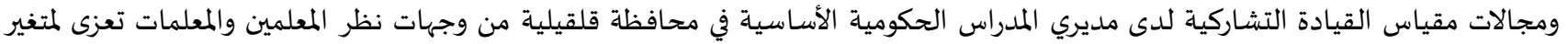

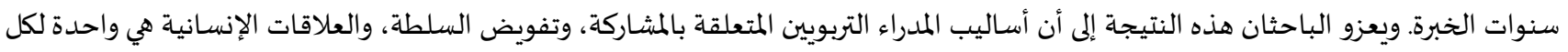

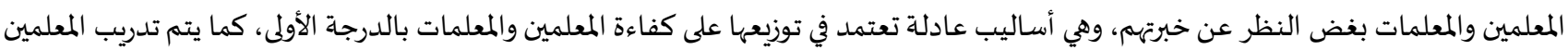

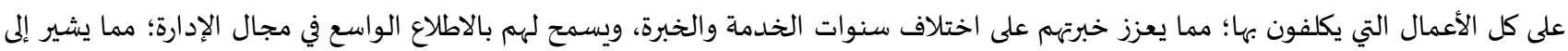

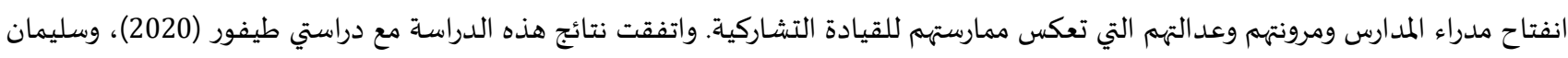

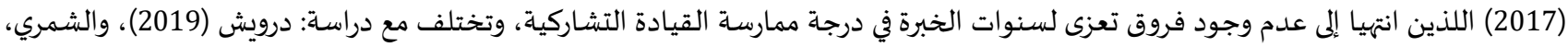

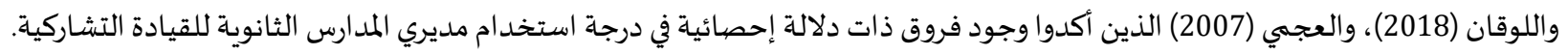

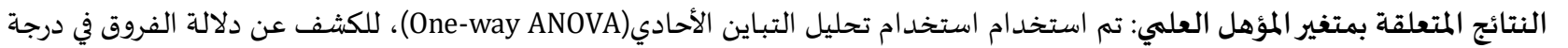

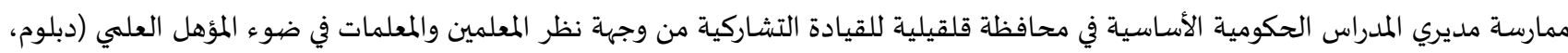
بكالوريوس، ماجستير فأعلى)، وكانت النتائج كما في جدول (11). 


\begin{tabular}{|c|c|c|c|c|c|c|}
\hline الدلالة الإحصائية & قيمة(ف) & متوسط & درجات الحرية & مجموع المربعات & مصدر التباين & المجالات \\
\hline \multirow[t]{3}{*}{0.180} & 1.736 & 0.467 & 2 & 0.935 & بين المجموعات & المشاركة في اتخاذ القرار \\
\hline & & 0.269 & 136 & 36.598 & داخل المجمموعات & \\
\hline & & & 138 & 37.533 & المجموع & \\
\hline \multirow[t]{3}{*}{0.094} & 2.407 & 0.944 & 2 & 1.888 & بين المجمموعات & تفويض السلطة \\
\hline & & 0.392 & 136 & 53.327 & داخل المجمموعات & \\
\hline & & & 138 & 55.215 & المجموع & \\
\hline \multirow[t]{3}{*}{$* 0.039$} & 3.318 & 1.478 & 2 & 2.957 & بين المجموعات & العلاقات الإنسانية \\
\hline & & 0.446 & 136 & 60.591 & داخل المجموعات & \\
\hline & & & 138 & 63.547 & المجموع & \\
\hline \multirow[t]{3}{*}{${ }^{*} 0.049$} & 3.080 & 0.900 & 2 & 1.800 & بين المجموعات & الدرجة الكلية \\
\hline & & 0.292 & 136 & 39.724 & داخل المجمموعات & \\
\hline & & & 138 & 41.524 & المجموع & \\
\hline
\end{tabular}

يتضح من جدول (11) وجود فروق ذات دلالة إحصائية بين متوسطات استجابات المعلمين في الدرجة الكلية وبعد العلاقات الإنسانية لمقياس

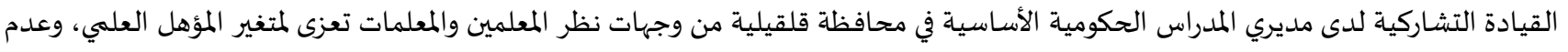

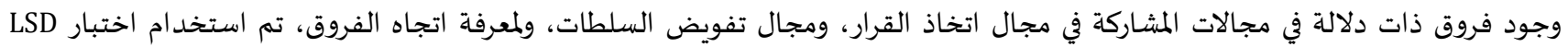

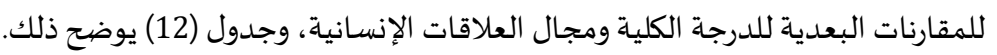
جدول (12): إختبار LSD للمقارنة البعدية للدرجة الكلية ومجال العلاقات الإنسانية

\begin{tabular}{|c|c|c|c|c|}
\hline ماجستير فأعلى & بكالوريوس & دبلوم & المؤهل العلهي & المجال \\
\hline 0.49396 & 0.09839 & - & دبلوم & العلاقات الإنسانية \\
\hline$* 0.39557$ & - & -0.09839 & بكالوريوس & \\
\hline- & *-0.39557 & -0.49396 & ماجستير فأعلى & \\
\hline 0.40587 & 0.10199 & - & 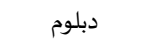 & الدرجة الكلية \\
\hline${ }^{*} 0.30388$ & - & -0.10199 & بكالوريوس & \\
\hline - & $-* 0.30388$ & -0.40587 & ماجستير فأعلى & \\
\hline
\end{tabular}

يشير جدول (12) إلى وجود فروق دالة إحصائياً عند مستوى الدلالة (م=0.05) في الدرجة الكلية ومجال العلاقات الإنسانية بين البكالوريوس

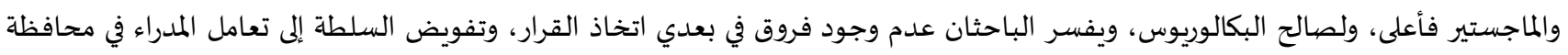

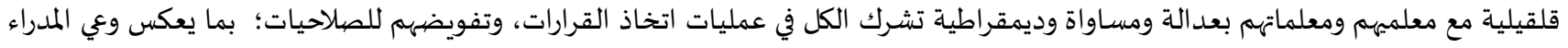

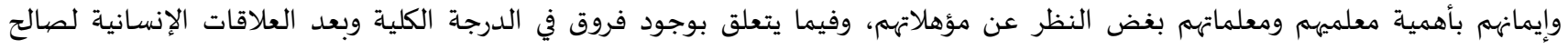

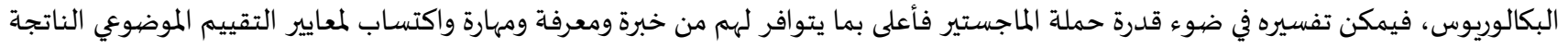

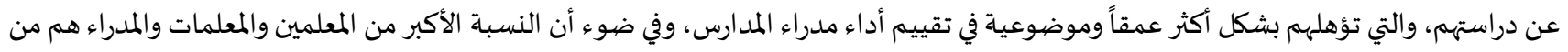

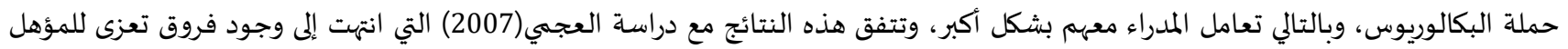

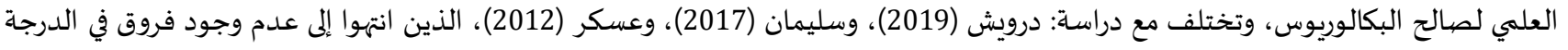
الكلية لمقياس القيادى التشاركية تعزى للمؤهل العلمي. إجابة السؤال الخامس والفرض الخاص به والذي ينص على "لا توجد فروق ذات دلالة إحصائية (م=0.05) في درجة ممارسة مديري المدراس الحكومية

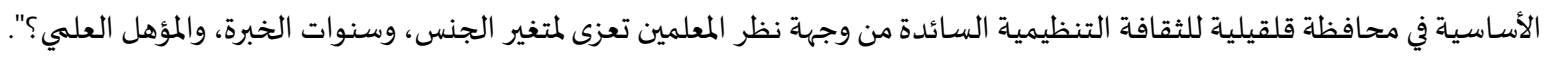
ولفحص الفرض السابق استخدمت الدراسة اختبار "ت" لمجموعتين مستقلتين، واختبار تحليل التباين الأحادي (One-way ANOVA)، وقد تم عرض نتائج كل متغير على حدة على النحو التالي:

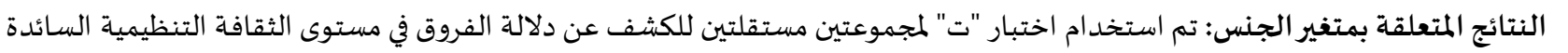

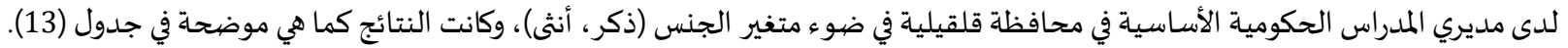




\begin{tabular}{|c|c|c|c|c|c|c|}
\hline \multirow[t]{2}{*}{ الدلالة } & \multirow[t]{2}{*}{ قيمة (ت) } & \multicolumn{2}{|c|}{ أنثى (ن =68) } & \multicolumn{2}{|c|}{ ذكر( ن=72) } & \multirow[t]{2}{*}{ المجال } \\
\hline & & الانحراف & المتوسط & الانحراف & المتوسط & \\
\hline$* 0.043$ & 2.04 & 0.64 & 3.74 & 0.64 & 3.97 & الهيكل التنظيمي \\
\hline$* 0.044$ & 2.03 & 0.67 & 3.81 & 0.61 & 4.04 & أنظمة الحوافز \\
\hline$* 0.024$ & 2.29 & 0.63 & 3.88 & 0.52 & 4.11 & العمليات \\
\hline$* 0.026$ & 2.25 & 0.61 & 3.81 & 0.55 & 4.04 & الدرجة الكلية \\
\hline
\end{tabular}

يتضح مِن جدول (13) وجود فروق ذات دلالة إحصائية عند مستوى الدلالة (م=0.05) بين متوسطات استجابات المعلمين في الدرجة الكلية

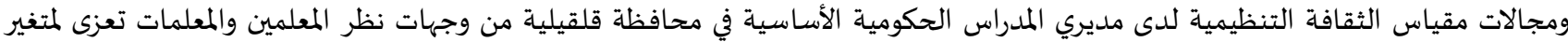

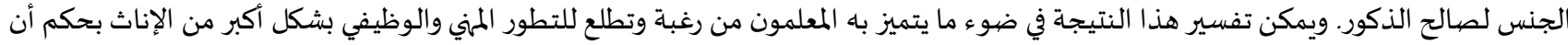

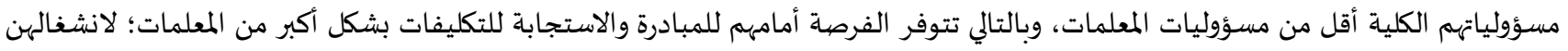
بآداء أدوارهن المختلفة كمعلمات وزوجات وأمهات، وبالتالي فرصة المعلمين متاحة بشكل أكبر للمشاركة في إعداد الهياكل التنظيمية، وفي التيات التخطيط

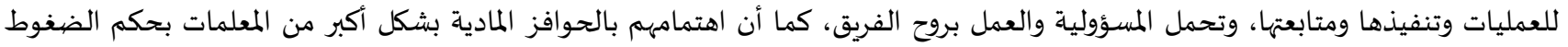

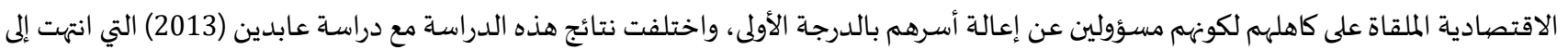
عدم وجود فروق في مستوى الثقافة التنظيمية تعزى لمتغير الجنس.

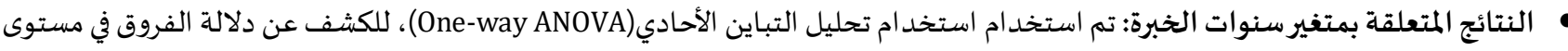

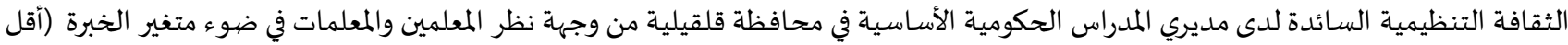
من 5 سنوات، من 5- 10 سنوات، أكثر من 10 سنوات سنواتئ)، وكانت المدات النتائج كما في جدول (14).

\begin{tabular}{|c|c|c|c|c|c|c|}
\hline الدلالة الإحصائية & قيمة(ف) & متوسط المربعات & درجات الحرية & مجموع المربعات & مصدر التباين & المجالات \\
\hline \multirow[t]{3}{*}{0.21} & 1.562 & 0.654 & 2 & 1.307 & بين المجموعات & الهيكل التنظيمي \\
\hline & & 0.418 & 136 & 56.906 & داخل المجموعات & \\
\hline & & & 138 & 58.213 & المجموع & \\
\hline \multirow[t]{3}{*}{0.43} & 0.850 & 0.358 & 2 & 0.717 & بين المجموعات & أنظمة الحو افز \\
\hline & & 0.422 & 136 & 57.333 & داخل المجموعات & \\
\hline & & & 138 & 58.050 & المجموع & \\
\hline \multirow[t]{3}{*}{0.08} & 2.490 & 0.845 & 2 & 1.690 & بين المجموعات & العمليات \\
\hline & & 0.339 & 136 & 46.151 & داخل المجموعات & \\
\hline & & & 138 & 47.841 & المجموع & \\
\hline \multirow[t]{3}{*}{0.20} & 1.591 & 0.552 & 2 & 1.103 & بين المجموعات & \\
\hline & & 0.347 & 136 & 47.148 & داخل المجموعات & الدرجة الكلية \\
\hline & & & 138 & 48.251 & المجموع & \\
\hline
\end{tabular}

يتضح من الجدول (14)عدم وجود فروق ذات دلالة إحصائية عند مستوى الدلالة (م=0.05) بين متوسطات استجابات المعلمين والمعلمات في

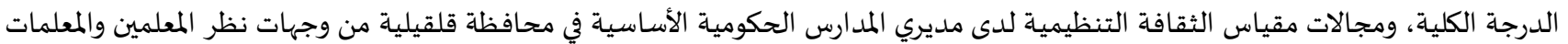

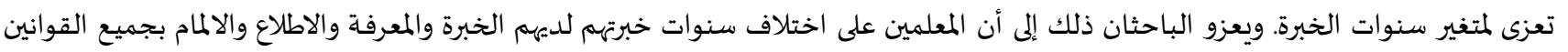

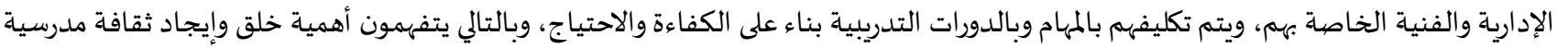

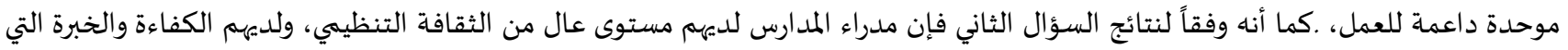

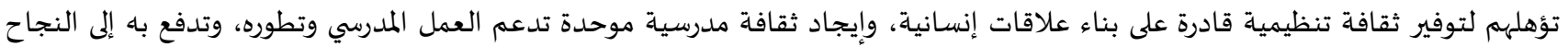

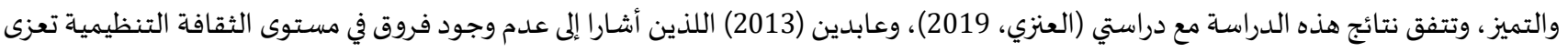
لسنوات الخبرة. 
•النتائج المتعلقة بمتغير المؤهل العلمي: تم استخدام استخدام تحليل التباين الأحادي(One-way ANOVA)، للكشف عن دلالة الفروق في مستوى الثقافة التنظيمية لدى مديري المدراس الحكومية الأساسية في محافظة قلقيلية من وجهة نظر المعلمين والمعلمات في ضوء المؤهل العلمي (دبلوم، بكالوريوس، ماجستير فأعلى)، وكانت النتائج كما في جدول (15).

\begin{tabular}{|c|c|c|c|c|c|c|}
\hline الدلالة الإحصائية & قيمة(ف) & متوسط & درجات الحرية & مجموع المربعات & مصدر التباين & المجالات \\
\hline \multirow[t]{3}{*}{0.053} & 2.994 & 1.209 & 2 & 2.417 & بين المجموعات & الهيكل التنظيمي \\
\hline & & 0.404 & 135 & 54.499 & داخل المجموعات & \\
\hline & & & 137 & 56.916 & المجموع & \\
\hline \multirow[t]{3}{*}{${ }^{*} 0.023$} & 3.863 & 1.549 & 2 & 3.099 & بين المجموعات & أنظمة الحو افز \\
\hline & & 0.401 & 135 & 54.138 & داخل المجموعات & \\
\hline & & & 137 & 57.237 & المجموع & \\
\hline \multirow[t]{3}{*}{$* 0.040$} & 3.297 & 1.099 & 2 & 2.199 & بين المجموعات & العمليات \\
\hline & & 0.333 & 135 & 45.007 & داخل المجموعات & \\
\hline & & & 137 & 47.206 & المجموع & \\
\hline \multirow[t]{3}{*}{${ }^{*} 0.024$} & 3.820 & 1.268 & 2 & 2.536 & بين المجموعات & الدرجة الكلية \\
\hline & & 0.332 & 135 & 44.820 & داخل المجموعات & \\
\hline & & & 137 & 47.356 & المجموع & \\
\hline
\end{tabular}

يتضح من جدول (15) وجود فروق في الدرجة الكلية ومجال أنظمة الحوافز ومجال العمليات، وعدم وجود فروق ذات دلالة إحصائية في مجال

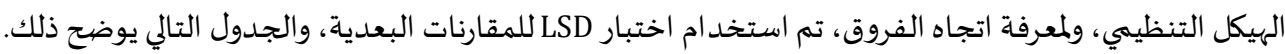
جدول (16): اختبار LSD للمقارنة البعدية للدرجة الكلية ومجال أنظمة الحو افز ومجال العمليات لمقياس الثقافة التنظيمية

\begin{tabular}{|c|c|c|c|c|}
\hline ماجستير فأعلى & بكالوريوس & دبلوم & المؤهل العلمي & المجال \\
\hline 0.45583 & 0.03295 & - & دبلوم & \\
\hline${ }^{*} 0.42288$ & - & -0.03295 & بكالوريوس & أنظمة الحو افز \\
\hline- & $-* 0.42288$ & -0.45583 & ماجستير فأعلى & \\
\hline 0.48250 & 0.14740 & - & دبلوم & العمليات \\
\hline${ }^{*} 0.33510$ & - & -0.14740 & بكالوريوس & \\
\hline- & $-* 0.33510$ & -0.48250 & ماجستير فأعلى & \\
\hline 0.46611 & 0.09209 & - & دبلوم & الدرجة الكلية \\
\hline${ }^{*} 0.37402$ & & -0.09209 & بكالوريوس & \\
\hline - & $-* 0.37402$ & -0.46611 & ماجستير فأعلى & \\
\hline
\end{tabular}

يشير جدول (16) إلى وجود فروق دالة إحصائياً عند مستوى الدلالة (م=0.05) في الدرجة الكلية، ومجال أنظمة الحوافز، ومجال العمليات بين البكالوريوس والماجستير فأعلى، ولصالح البكالوريوس. ويعزو الباحثان هذه النتيجة إلى أن حملة الماجستير فأعلى لديهم الخبرة الأكبر في التقييم والحكم على الأمور، ولديهم خبرة أوسع والتي اكتسبوها من خلال دراستهم، كما يشكل حملة البكالوريوس النسبة الأكبر من المعلمين والمعلمات والمدراء في المدارس الحكومية، وبالتالي إشراكهم بشكل أكبر بالهيكل التنظيمي، وفي تخطيط العيمة العمليات وتنفيذها ومتابعتها وتقويمها، ودعمههم من خلال أنظمة الحوافز المتاحة من قبل المدراء بشكل أكبر بحكم أنهم الشريحة الأوسع، التي تملك الخبرة الواسعة، والتي يحرص المدراء على فاعليتهم في المؤسسة

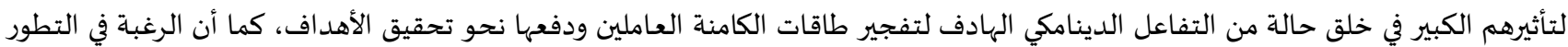
المهني تكون أكبر لدى حملة البكالوريوس كونهم ما زالوا يتطلعون لفرص تحسن وضعهم الأكاديمي والوظيفي والمهني، وتتفق هذه النتائج مع نتائج دراستي

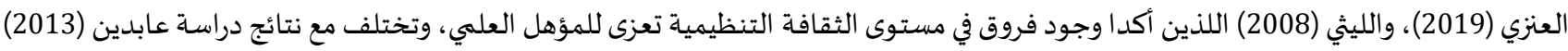
التي أشـارت إلى عدم وجود فروق في مستوى الثقافة التنظيمية تعزى للمؤهل العلمي. 
توصيات الدراسـة:

في ضوء النتائج السابقة، توصبي الدراسة بما يلي: تبني قادة المدارس لمنحى القيادة التشاركية كاتجاه فعال في القيادة المدرسية، من خلال إشراك المعلمين في عمليات التخطيط والتنفيذ والمتابعة والتقويم، وفي إعداد الخطط المدرسية، وعمليات اتخاذ القرار.

ه العمل على تطوير القيادات المدرسية من خلال إلحاقهم بدورات تدريبية حول الاتجاهات الحديثة في القيادة المدرسية، والثقافة التنظيمية. توجه مدراء المدارس؛ لتعزيز العلاقات الإنسانية مع معلميهم لتوفير المناخ الإيجابي. توجاء المدراء لنشر ثقافة تنظيمية تشجع الإبداع والابتكار والتجديد في بيئة العمل متعلقة بكل جانب من جوانب العملية التعليمية.

مقترحات بحثية:

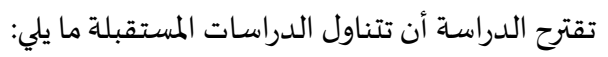
فاعلية برنامج تدريبي في تنمية اتجاه القيادة التشاركية لدى مدراء المدارس الحكومية في الضفة الغربية. الثقافة التنظيمية وعلاقتها بالابداع الإداري والرضا الوظيفي لدى مديري المدارس في الضفة الغربية. تأثير الثقافة التنظيمية على جودة الأداء لدى معلمي المدارس الحكومية في الضفة الغربية.

1. أبو بكر، مصطفى محمود، (2000). التفكير الإسلامي واعد/د الخطة/الاستراتيجية. الدار الجامعية للطباعة والنشر والتوزيع، القاهرة. 2. الحربي، قاسم بن عائل (2004). القيادة الملدرسية في ضيوء اتجباهات القيادة التوبوية الحسيثة. مكتبة الرشد للنشر والتوزيع، الرياض.

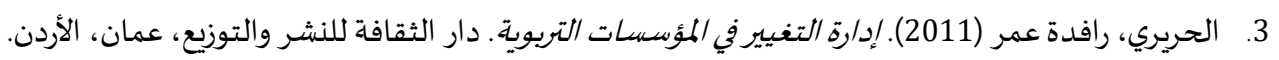
4. حريم، حسين (2004). السلوك التنظيهي سلوك الأفراد والجماعات في منظمات الأعمال. دار الحامد للنشر والتوزيع، الأردن.

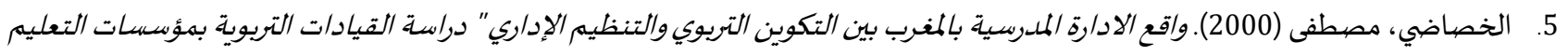

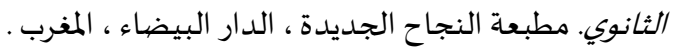
6. الخصاونة، فؤاد شبيب. (2019). درجة ممارسة قادة مدارس التعليم العام في منطقة نجران للقيادة التشاركية وعلاقتها بمستوى الإبلاع الإداري

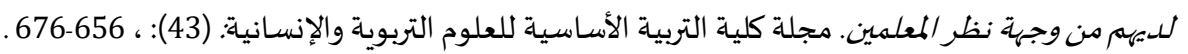
7.

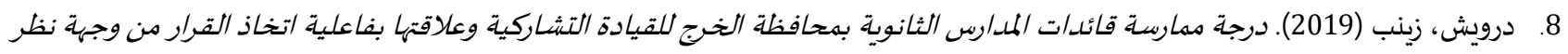
المعلمات. مجلة الجامعة الإسلامية للدراسات النفسية والتربوية: 27(5): 310-310. 9 9. الرباعي، خولة ابراهيم (2009). درجة مشاركة معلمي الممدارس الثانوية الخاصة في الأردن في اتخاذ القرارات الملمرسية وعلاقاتها برضاهم الوظيفي وانتمائهم المنهي. رسالة دكتوراه، جامعاة عمان العربية للدراسات العليا، الأردن .

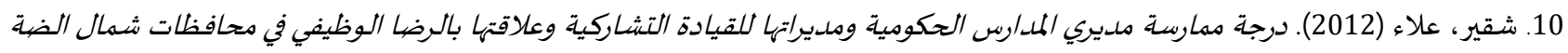
الغربية من وجهات نظر المعلمين والمعلمات. رسالة ماجستير، جامعاة النجاح، فلسطين.

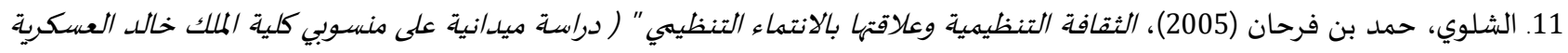
المدنيين والعسكريين ). رسالة ماجستير، جامعة نايف العربية للعلوم الأمنية ، المملكة العربية السعودية .

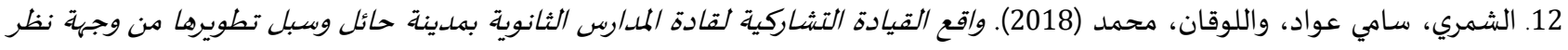

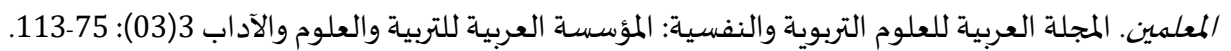
13. الصليبي، عائد (2015). درجة ممارسة ملديري المدارس الثانوية بمحافظة غزة للقيادة التشاركية وعلاقتها بالفاعلية الذاتية لمعلميهم. رسالة ماجستير، الجامعة الإسلامية غزة. 14. طيفور، هيفاء علي محمود (2020). درجة ممارسة قادة الممدرس في محافظة عجلون للقيادة التشاركية ومقترحات تطويرها من وجهة نظر

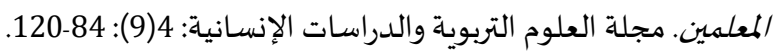
15. عابدين، محمد (2013). مستوى الثقافة التنظيمية في المدارس الثانوية في محافظة القدس كمانسا يراه الإد/ريون والمعلمون. مجلة العلوم التربوية والنفسية: 14(1): 41-10-70. 
16. العجمي، محمد (2007). درجة استخدام مديري المدارس الثانوية في دولة الكويت لنمط الإد/رة التشاركية عند ليكرت من وجهة نظر المعلمين. رسالة ماجستير، جامعة عمان العربية للدراسات العليا، الأردن.

17. العرابيد، نبيل (2010). دور القيادة التشاركية في مديريات التربية والتعليم في حل مشككلات مديري المدارس الثانس الثانوية بمحافظات غزة. رسالة

ماجستير غير منشورة. جامعة الأزهر، غزة.

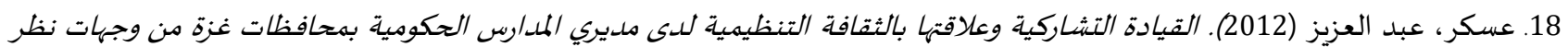

المعلمين. رسالة ماجستير، جامعة الأزهر ،غزة

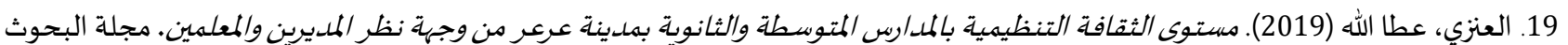

التربوية: 16 (61): 109-135.

20. العميان، محمود سلمان(2010). السلوك التنظيمي في منظمات الأعمال. دار وائل للنشر، عمان.

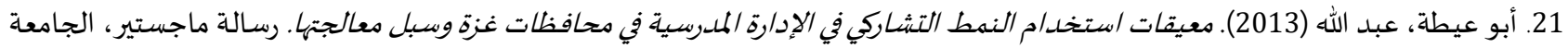

الإسلامية، غزة.

22. الغالبي، طاهر، وإدريس، ووائل (2009). الإدارة الاستراتيجية منظور منهجي متكامل. ط2 ، دار وائل للطباعة والنشر ، عمان، الأردن.

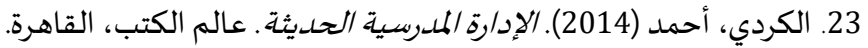

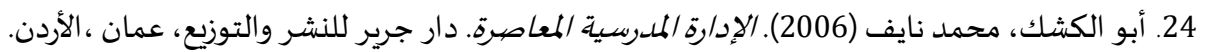

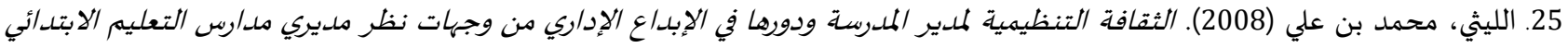

بالعاصمة المقلسة. رسالة ماجستير، كلية التربية، جامعة أم القرى، المملكة العربية السعودية.

26. الليمون ، شاهر قبلان (2019). درجة ممارسة مديري المدارس الثانوية الحكومية في الأردن للقيادة التحويلية وعلاقتها بأنماط الثقافة التنظيمية لتلك المدارس. رسالة دكتوراه، الجامعة الأردنية، الأردن.

27. محسن، عبد العزيز (2012). أثر نمطي القيادة التشاركية والتحويلية في تحسين الأداء الوظيفي: دراسة مقارنة في المستشفيات الأردنية ، رسالة دكتوراه. جامعة عمان الأهلية، عمان، الأردن.

28. المحمادي، خالد (2015). درجة مماربسة مديري مكاتب التوبية والتعليم بمكة المكرمة للقيادة التشاركية وعلاقتها بالروح المعنوية من وجهة نظر التهر المشـرفين. رسالة ماجستير، جامعة أم القرى، المملكة العربية السعودية.

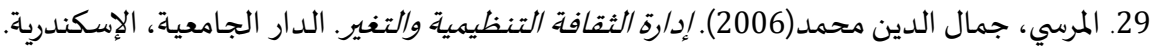

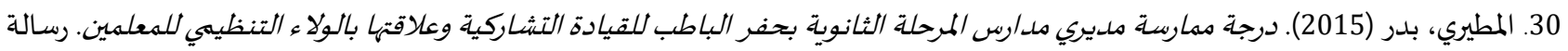

ماجستير، جامعة أم القرى، مكة المكرمة.

ثانياً: المراجع الأجنبية:

1. Boyce, A. S., Nieminen, L. R., Gillespie, M. A., Ryan, A. M., \& Denison, D. R. (2015). Which comes first, organizational culture or performance? A longitudinal study of causal priority with automobile dealerships. Journal of Organizational Behavior, 36(3): 339-359, https://doi.org/10.1002/job.1985.

2. Chipunza, C., \& Malo, B., (2017). Organizational culture and job satisfaction among academic professionals at a South African university of technology. Problems and Perspectives in Management,15(2): 148-161, https://doi.org/10.21511/ppm.15(2).2017.14.

3. Desselle, S. P., Raja, L., Andrews, B., \& Lui, J. (2018). Perceptions of organizational culture and organizational citizenship by faculty in US colleges and schools of pharmacy. Currents in Pharmacy Teaching and Learning, 10(4): 403-412, https://doi.org/10.1016/j.cptl.2017.12.017.

4. Efanga, S. \& Ifejiagwa, O., (2013). Influence of Organizational Culture on Performance Management Practices in Secondary Schools in Akwa Ibom State, Nigeria, International Journal of Humanities and Social Science, 4(6):300-304.

5. Ghinea, V., Mihaylova, L. \& Papazov, E., (2015). Organizational Culture Dynamics. Complex Systems Dynamics. Quality Access to Success, 16 (147) 99-105.

6. George, B. \& John, G. (2008). People-based leadership: Enriching a work culture. for world-class safety, Professional Saftey, 53(3): 29-36

7. Hatch, M. J. (1993). The dynamics of organizational culture. Academy of management review, 18(4): 657-693.

8. Huang, X., Iun, J., Liu, A., \& Gong, Y. (2010). Does participative leadership enhance work performance by inducing empowerment or trust? The differential effects on managerial and non-managerial subordinates. Journal of Organizational Behavior, 31(1): 122-143, https://doi.org/10.1002/job.636. 
9. Koşar, D., \& Yalçınkaya, M., (2013). Öğretmenlerin örgütsel vatandaşlık davranışlarının yordayıcıları olarak örgüt kültürü ve örgütsel güven (Organizational culture and organizational trust as predictors of teachers' organizational citizenship behaviors), Educational Administration: Theory and Practice, 19(4): 603-627.

10. Liu, Z., Cai, Z., Li, J., Shi, S. \& Fang, Y., (2013). Leadership style loyee turnover intentions: A Scosial identity perspective, Career Development International, 18(3): 305-324, https://doi.org/10.1108/cdi-09-2012-0087.

11. Mintari, S., Shabri, A., (2020). Enhancing Performance through Improving Participatory Leadership Work Engagement and Compensation. Sumerianz, Journal of Business and Marketing, 3(4): 28-37.

12. Mokoena, S. (2017). Effective Participateive Management: Does it Affect Trust Levels of Stakeholders in Schoo?, Journal if Sicial Sciences, 30(1): 43-53, https://doi.org/10.1080/09718923.2012.11892981.

13. Pardo, M., \& Martinez, C., \& Roig, S., (2012). Participative Management and Its Influence on Organizational Change, Management Decision, 50(10): 1843-1860, https://doi.org/10.1108/00251741211279639.

14. Schein, E., (2010). Organizational culture and leadership, 4 edition, Sanfransisco, CA: Jossey-Bass.

15. Sergiovanni, T., (2000). The lifeworld of leadership. San Francisco, CA: Jossey-Bass Şişman, M. (2002a), Örgütler ve Kültürler, Ankara, Pegem A Yayıncılık

16. Szymanska. K.,(2016). Organisational culture as a part in the development of open innovation - the perspective of small and medium-sized enterprises. Management, 20(1):142-154, https://doi.org/10.1515/manment-2015-0030.

17. Trice, H. M., \& Beyer, J. M. (1993). The cultures of work organizations. Prentice-Hall, Inc. 
المجلة الدولية للدراسـات التربوية والنفسية

International Journal of Educational \& Psychological Studies (EPS)

Journal Homepage: https://www.refaad.com/views/EPSR/Home.aspx

www.refaad.com

ISSN: 2520-4149 (Online) 2520-4130 (Print)

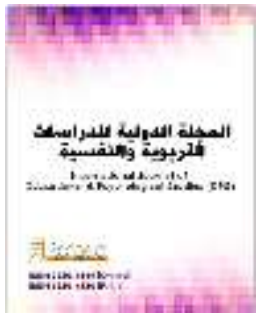

\title{
Participatory leadership and its relationship to the organizational culture of basic governmental school principals in qalqilya governorate as perceived by male teachers and female teachers
}

\author{
Goltan Hassan Hijazi \\ Professor of Psychology, Palestine Technical University/ Khadouri, Palestine \\ joltanhijazi@gmail.com
}

Shadi Khalid Qashoo

Educational Researcher- PhD Program in Educational Administration, Arab American University, Palestine

Received : 29/7/2020 Revised : 11/8/2020 Accepted : 20/8/2020 DOI : https://doi.org/10.31559/EPS2021.9.2.20

Abstract: The study aimed to examine the relationship between the degree to which principals of basic public schools in Qalqilya governorate, Palestine, practice participatory leadership, and the level of organizational culture prevailing among them as perceived by male and female teachers. Furthermore, the study wanted to identify the nature of the differences in the degree to which school principals' practice participatory leadership, and their level of organizational culture attributable to variables of (Gender years of experience - educational qualification). The study used the Participatory Leadership Scale and the Organizational Culture Scale. The sample consisted of (140) male and female teachers from the basic government schools in Qalqilya governorate. The results showed that the degree of school principals' practice of participatory leadership was high, with an average of (3.87), and a percentage of (77.4\%). the level of organizational culture among the principals was high, with a mean of (3.93) and a percentage of (78.6\%). The results showed a statistically significant positive correlation $(\alpha=0.05)$ between the degree of school principals' practice of participatory leadership and the level of organizational culture they had as perceived by the respondents. The results did not show statistically significant differences in the scores of the study sample on the participatory leadership scale due to the gender variable except for the dimension of human relations, and the differences were in favor of males, while differences were found attributable to academic qualification in the total score of the scale, and in the human relations dimension in favor of the bachelor degree holders compared to the master's degree and above, and those differences did not appear according to the variable of years of experience. Besides, the results showed that there were statistically significant differences in the degrees of the study sample on the scale of organizational culture and its dimensions attributable to gender, in favor of males, as well as in the total score of the scale, and on the dimensions of incentive systems and processes attributable to academic qualification in favor of the bachelor degree holders versus master degree holders and higher. However, no statistically significant differences appeared in the level of organizational culture prevailing among school principals attributable to years of experience as perceived by the respondents.

Keywords: participatory leadership; organizational culture; Qalqilya Governorate.

References:

1. Abw Bkr, Mstfa Mhmwd, (2000). Altfkyr Aleslamy Wa'dad Alkhthalastratyjyh. Aldar Aljam'yh Lltba'h Walnshr Waltwzy', Alqahrh.

2. Alhrby, Qasm Bn 'a'l (2004). Alqyadh Almdrsyh Fy Dw' Atjahat Alqyadh Altrbwyh Alhdythh. Mktbt Alrshd Llnshr Waltwzy', Alryad.

3. Alhryry, Rafdh 'mr (2011). Edart Altghyyr Fy Alm'ssat Altrbwyh. Dar Althqafh Llnshr Waltwzy', 'man, Alardn.

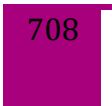

المجلة الدولية للدراسات التربوية والنفسية- المجلد9، العدد2- 2021، ص: 690-709 
4. Hrym, Hsyn (2004). Alslwk Altnzymy Slwk Alafrad Waljma'at Fy Mnzmat Ala'mal. Dar Alhamd Llnshr Waltwzy', Alardn.

5. Alkhsady, Mstfa (2000). Waq' Aladarh Almdrsyh Balmghrb Byn Altkwyn Altrbwy Waltnzym Aledary " Drast Alqyadat Altrbwyh Bm'ssat Alt'lym Althanwy. Mtb't Alnjah Aljdydh, Aldar Albyda' , Almghrb .

6. Alkhsawnh, F'ad Shbyb. (2019). Drjt Mmarst Qadt Mdars Alt'lym Al'am Fy Mntqh Njran Llqyadh Altsharkyh W'laqtha Bmstwa Alebda' Aledary Ldyhm Mn Wjht Nzr Alm'lmyn. Mjlt Klyt Altrbyh Alasasyh Ll'lwm Altrbwyh Walensanyh: (43): 656-676.

7. Khlyl, Mhmd (2013). Aleshraf Altrbwy Alhdyth: Almahyh Walahdaf Walanwa' Walasalyb. Dar Mjdlawy Llnshr Waltwzy', 'man, Alardn.

8. Drwysh, Zynb (2019). Drjt Mmarst Qa'dat Almdars Althanwyh Bmhafzh Alkhrj Llqyadh Altsharkyh W'laqtha Bfa'lyt Atkhad Alqrar Mn Wjht Nzr Alm'Imat. Mjlt Aljam'h Aleslamyh Lldrasat Alnfsyh Waltrbwyh: 27(5): 310-341.

9. Alrba'y, Khwlh Abrahym (2009). Drjt Msharkt M'lmy Almdars Althanwyh Alkhash Fy Alardn Fy Atkhad Alqrarat Almdrsyh W'laqatha Brdahm Alwzyfy Wantma'hm Almhny. Rsalh Dktwrah, Jam't 'man Al'rbyh Lldrasat Al'lya, Alardn.

10. Shqyr, 'la' (2012). Drjt Mmarst Mdyry Almdars Alhkwmyh Wmdyratha Llqyadh Altsharkyh W'laqtha Balrda Alwzyfy Fy Mhafzat Shmal Aldh Alghrbyh Mn Wjhat Nzr Alm'lmyn Walm'lmat. Rsalh Majstyr, Jam't Alnjah, Flstyn.

11. Alshlwy, Hmd Bn Frhan (2005), Althqafh Altnzymyh W'laqtha Balantma' Altnzymy " (Drash Mydanyh 'la Mnswby Klyt Almlk Khald Al'skryh Almdnyyn Wal'skryyn). Rsalt Majstyr, Jam't Nayf Al'rbyh Ll'lwm Alamnyh, Almmlkh Al'erbyh Als'wdyh.

12. Alshmry, Samy 'wad, Wallwqan, Mhmd (2018). Waq' Alqyadh Altsharkyh Lqadh Almdars Althanwyh Bmdynh Ha'l Wsbl Ttwyrha Mn Wjht Nzr Alm'lmyn. Almjlh Al'rbyh Ll'lwm Altrbwyh Walnfsyh: Alm'ssh Al'rbyh Lltrbyh Wal'lwm Waladab 3(03): 75-113.

13. Alslyby, 'a'd (2015). Drjh Mmarsh Mdyry Almdars Althanwyh Bmhafzh Ghzh Llqyadh Altsharkyh W'laqtha Balfa'lyh Aldatyh Lm'lmyhm. Rsalt Majstyr, Aljam'h Aleslamyh Ghzh.

14. Tyfwr, Hyfa' 'ly Mhmwd (2020). Drjt Mmarsh Qadh Almdars Fy Mhafzh 'jlwn Llqyadh Altsharkyh Wmqtrhat Ttwyrha Mn Wjhh Nzr Alm'lmyn. Mjlt Al'lwm Altrbwyh Waldrasat Alensanyh: 4(9): 84-120.

15. 'abdyn, Mhmd (2013). Mstwa Althqafh Altnzymyh Fy Almdars Althanwyh Fy Mhafzt Alqds Kma Yrah Aledarywn Walm'lmwn. Mjlt Al'lwm Altrbwyh Walnfsyh: 14(1): 41-70.

16. Al'jmy, Mhmd (2007). Drjt Astkhdam Mdyry Almdars Althanwyh Fy Dwlt Alkwyt Lnmt Aledarh Altsharkyh 'nd Lykrt Mn Wjht Nzr Alm'Imyn. Rsalh Majstyr, Jam't 'man Al'rbyh Lldrasat Al'lya, Alardn.

17. Al'rabyd, Nbyl (2010). Dwr Alqyadh Altsharkyh Fy Mdyryat Altrbyh Walt'lym Fy Hl Mshklat Mdyry Almdars Althanwyh Bmhafzat Ghzh. Rsalt Majstyr Ghyr Mnshwrh. Jam't Alazhr, Ghzh.

18. 'skr, 'bd Al'zyz (2012). Alqyadh Altsharkyh W'laqtha Balthqafh Altnzymyh Lda Mdyry Almdars Alhkwmyh Bmhafzat Ghzh Mn Wjhat Nzr Alm'elmyn. Rsalt Majstyr, Jam't Alazhr, Ghzh

19. Al'nzy, 'ta Allh (2019). Mstwa Althqafh Altnzymyh Balmdars Almtwsth Walthanwyh Bmdynh 'r'r Mn Wjht Nzr Almdyryn Walm'lmyn. Mjlt Albhwth Altrbwyh: 16 (61): 109-135.

20. Al'myan, Mhmwd Slman (2010). Alslwk Altnzymy Fy Mnzmat Ala'mal. Dar Wa'l Llnshr, 'man.

21. Abw 'yth, 'bd Allh (2013). M'yqat Astkhdam Alnmt Altsharky Fy Aledarh Almdrsyh Fy Mhafzat Ghzh Wsbl M'aljtha. Rsalt Majstyr, Aljam'h Aleslamyh, Ghzh.

22. Alghalby, Tahr, Wedrys, Wwa'el (2009). Aledarh Alastratyjyh Mnzwr Mnhjy Mtkaml. T2, Dar Wa'l Lltba'h Walnshr, 'man, Alardn.

23. Alkrdy, Ahmd (2014). Aledarh Almdrsyh Alhdythh. 'alm Alktb, Alqahrh.

24. Abw Alkshk, Mhmd Nayf (2006). Aledarh Almdrsyh Alm'asrh. Dar Jryr Llnshr Waltwzy', 'man, Alardn.

25. Allythy, Mhmd Bn 'Ely (2008). Althqafh Altnzymyh Lmdyr Almdrsh Wdwrha Fy Alebda' Aledary Mn Wjhat Nzr Mdyry Mdars Alt'lym Alabtda'y Bal'asmh Almqdsh. Rsalt Majstyr, Klyh Altrbyh, Jam't Am Alqra, Almmlkh Al'rbyh Als'ewdyh.

26. Allymwn, Shahr Qblan (2019). Drjt Mmarsh Mdyry Almdars Althanwyh Alhkwmyh Fy Alardn Llqyadh Althwylyh W'laqtha Banmat Althqafh Altnzymyh Ltlk Almdars. Rsalt Dktwrah, Aljam'h Alardnyh, Alardn.

27. Mhsn, 'bd Al'zyz (2012). Athr Nmty Alqyadh Altsharkyh Walthwylyh Fy Thsyn Alada' Alwzyfy: Drash Mqarnh Fy Almstshfyat Alardnyh, Rsalt Dktwrah. Jam't 'man Alahlyh, 'man, Alardn.

28. Almhmady, Khald ((2015. Drjh Mmarsh Mdyry Mkatb Altrbyh Walt'lym Bmkh Almkrmh Llqyadh Altsharkyh W'laqtha Balrwt Alm'nwyh Mn Wjht Nzr Almshrfyn. Rsalh Majstyr, Jam't Am Alqra, Almmlkh Al'rbyh Als'wdyh.

29. Almrsy, Jmal Aldyn Mhmd (2006). Edart Althqafh Altnzymyh Waltghyr. Aldar Aljam'yh, Aleskndryh.

30. Almtyry, Bdr (2015). Drjt Mmarst Mdyry Mdars Almrhlh Althanwyh Bhfr Albatb Llqyadh Altsharkyh W'laqtha Balwla' Altnzymy Llm'Imyn. Rsalt Majstyr, Jam't Am Alqra, Mkh Almkrmh. 